\title{
Development of a genetically encoded sensor for endogenous CaMKII activity
}

4 Goli Ardestani*1,2,5 , Megan West* ${ }^{3,5}$, Thomas J. Maresca ${ }^{4,5}$, Rafael A. Fissore ${ }^{1,5}$,

6 Margaret M. Stratton 3,5

Department of Veterinary and Animal Sciences ${ }^{1}$, Molecular and Cellular Biology

8 Program $^{2}$, Department of Biochemistry and Molecular Biology ${ }_{5}^{3}$, Department of Biology ${ }^{4}$, University of Massachusetts, Amherst, United States ${ }^{5}$

\section{ABSTRACT}

12 CaMKII is a crucial oligomeric enzyme in neuronal and cardiac signaling, fertilization and immunity. Here, we report the construction of a novel, substrate-based, genetically-encoded

14 sensor for CaMKII activity, FRESCA (FRET-based Sensor for CaMKII Activity). Currently, there is one biosensor for CaMKII activity, Camui, which contains CaMKII. FRESCA allows us

16 to measure all endogenous CaMKII variants, while Camui can track a single variant. Since there are $\sim 40 \mathrm{CaMKII}$ variants, using FRESCA to measure aggregate activity allows a fresh

18 perspective on CaMKII activity. We show, using live-cell imaging, FRESCA response is concurrent with $\mathrm{Ca}^{2+}$ rises in HEK293T cells and mouse eggs. In eggs, we stimulate oscillatory

20 patterns of $\mathrm{Ca}^{2+}$ and observe the differential responses of FRESCA and Camui. Our results implicate an important role for the variable linker region in CaMKII, which tunes its activation.

22 FRESCA will be a transformative tool for studies in neurons, cardiomyocytes and other CaMKIIcontaining cells.

\section{INTRODUCTION}

26 Calcium-calmodulin dependent protein kinase II (CaMKII) is a serine/threonine kinase that plays critical signaling roles in multiple mammalian tissues (Backs et al., 2010;

28 Rokita \& Anderson, 2012; Shonesy, Jalan-Sakrikar, Cavener, \& Colbran, 2014) and is 
implicated in a number of diseases (Mollova, Katus, \& Backs, 2015; Robison, 2014;

2 Steinkellner et al., 2012; Tu, Okamoto, Lipton, \& Xu, 2014). CaMKII plays a key role in all electrically coupled cells, such as neurons and cardiomyocytes, and even cells that are

4 not - such as lymphocytes and eggs - all of which communicate using $\mathrm{Ca}^{2+}$. Depending on the stimulus, the $\mathrm{Ca}^{2+}$ response leads is either a single $\mathrm{Ca}^{2+}$ rise or a more complex

6 responses such as oscillations (Cuthbertson, Whittingham, \& Cobbold, 1981; Eisner, Caldwell, Kistamas, \& Trafford, 2017; Rutecki, 1992; Swann \& Lai, 2013). Absence of

$8 \mathrm{Ca}^{2+}$ signals causes severe defects in cell functionality, such as memory deficits in the case of neurons (Herring \& Nicoll, 2016), or in the case of fertilization, failure to

10 conceive (Escoffier et al., 2016; Yoon et al., 2008). CaMKII is responsible for reacting to $\mathrm{Ca}^{2+}$ oscillations and transducing this signal to downstream molecules. Indeed, it has been

12 shown that neuronal CaMKII has a threshold frequency for activation (Chao et al., 2011; De Koninck \& Schulman, 1998).

CaMKII has a unique oligomeric structure among the protein kinase family (Fig. 1A).

16 Each subunit of CaMKII is comprised of a kinase domain, regulatory segment, variable linker region, and hub domain (Fig. 1B). The hub domain is responsible for

18 oligomerization, which organizes into two stacked hexameric (or heptameric) rings to form a dodecameric (or tetradecameric) holoenzyme (Bhattacharyya et al., 2016; Chao et

20 al., 2011; Rosenberg et al., 2006). In the absence of $\mathrm{Ca}^{2+}$, the regulatory segment binds to and blocks the substrate-binding pocket. $\mathrm{Ca}^{2+} /$ calmodulin $\left(\mathrm{Ca}^{2+} / \mathrm{CaM}\right)$ turns $\mathrm{CaMKII}$ on

22 by competitively binding the regulatory segment and exposing the substrate-binding pocket (Fig. 1C). 
2 It has been demonstrated that CaMKII has a threshold frequency for activation (Chao et al., 2011; De Koninck \& Schulman, 1998). There are four human CaMKII genes;

$4 \mathrm{CaMKII} \alpha$ and $\beta$ are predominantly expressed in neurons, CaMKII $\delta$ is predominantly expressed in the heart and CaMKII $\gamma$ is found in multiple organ systems, including the

6 reproductive organs. The kinase and hub domains of all four genes are highly conserved ( $\sim 90 \%$ on average), however, the linker domain connecting the kinase and hub domains

A

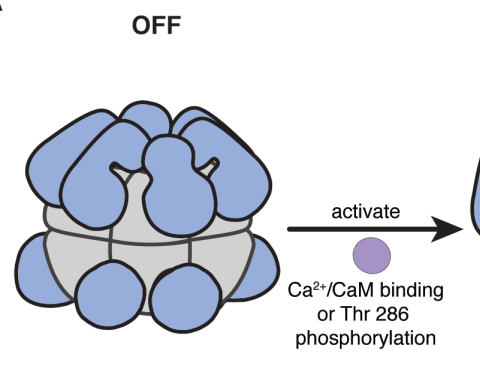

C

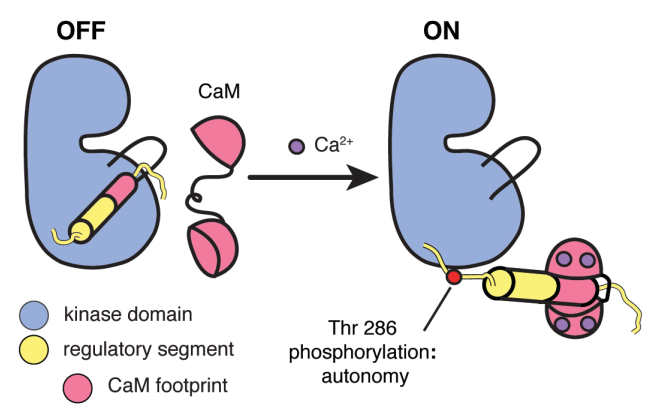

B

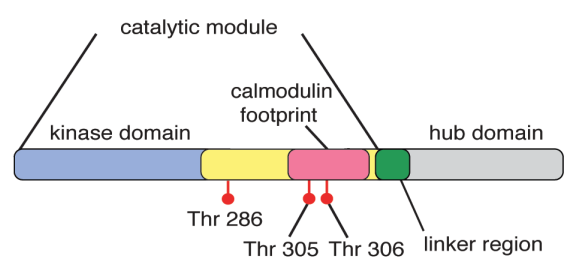

$\mathrm{D}$

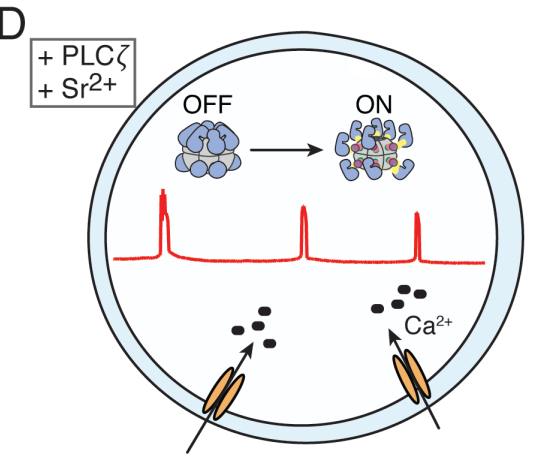

Figure 1. CaMKII: an essential enzyme. A) CaMKII is an oligomeric complex turned on by $\mathrm{Ca}^{2+} / \mathrm{CaM}$ binding, which facilitates phosphorylation at Thr 286. B) Each CaMKII subunit is comprised of a kinase domain, regulatory segment which houses the $\mathrm{CaM}$ binding domain, a variable linker region, and a hub domain. C) The regulatory segment of CaMKII maintains its off state in the absence of calcium by blocking its substrate binding pocket. $\mathrm{Ca}^{2+} / \mathrm{CaM}$ competes with the regulatory segment, thereby activating the kinase and allowing for Thr286 phosphorylation, which yields autonomous activity. Even when the calcium stimulus diminishes, CaMKII stays on as long as Thr 286 is phosphorylated. D) In mammalian eggs, addition of PLC $\zeta$ or $\mathrm{Sr}^{2+}$ leads to stimulation of calcium oscillations and CaMKII activation. CaMKII is expected to be "off" in the absence of $\mathrm{Ca}^{2+}$ and turn "on" after $\mathrm{Ca}^{2+}$ levels rise. 
is variable in length and composition. Details elucidating the importance of the variable

2 linker region remain to be uncovered, but there are $>30$ different splice variants of each of the four genes, which mostly vary in the linker region only. It has been shown that

4 CaMKII activity is tuned by the length of the variable linker in vitro (Bayer, De Koninck, \& Schulman, 2002; Chao et al., 2011). Specifically, as the variable linker is lengthened,

6 less $\mathrm{Ca}^{2+}$ is needed for activation (i.e., activation of CaMKII is easier). Thus, it is important for us to consider the complexity of endogenous CaMKII expressed in various

8 cell types.

10 Camui is currently the only biosensor for CaMKII activity (Takao et al., 2005). Camui is a Förster resonance energy transfer (FRET)-based biosensor for CaMKII activity, which

12 exploits the conformational change that CaMKII undergoes when it binds to $\mathrm{Ca}^{2+} / \mathrm{CaM}$ (Fig. 2A). To date, Camui has been a very useful tool to study and understand CaMKII

14 activity in various cell types (mainly neurons and cardiomyocytes) and under various conditions (Erickson, Patel, Ferguson, Bossuyt, \& Bers, 2011; Kwok et al., 2008; Takao

16 et al., 2005). However, a major limitation is that the Camui sensor is constructed of a CaMKII variant itself, and thus will only report on this particular variant. To enhance our 18 understanding of this complex protein, we need a way to measure endogenous CaMKII activity. One option is to re-engineer Camui with the appropriate CaMKII isoform to be

20 studied, however this becomes limiting when there are multiple isoforms expressed in a single cell type, such as during the development of the female gamete, the egg. We now

22 report the development of a novel biosensor that detects endogenous CaMKII activity. Herein, we show the efficacy of this new sensor in mouse eggs. 


\section{RESULTS AND DISCUSSION}

2 Development of a novel biosensor for endogenous CaMKII activity

We developed a novel substrate-based sensor for CaMKII activity, FRESCA (FRET

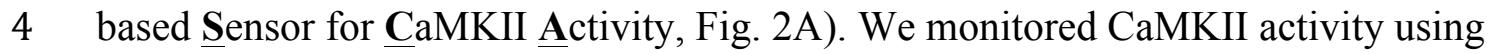
FRESCA in real-time following the induction of $\mathrm{Ca}^{2+}$ responses to several agonists that

6 are capable of initiating egg activation and embryogenesis. Building on a previous design for an Aurora kinase biosensor (Liu, Vader, Vromans, Lampson, \& Lens, 2009), we

8 replaced the sequence encoding the Aurora kinase substrate for the CaMKII substrate (syntide). The design also employs FHA2, a phosphate-binding domain, to facilitate a

10 conformational change once the adjacent CaMKII substrate is phosphorylated (Durocher et al., 2000). FHA2 will bind to this phosphorylated Thr residue and produce a decrease

12 in FRET between the terminal CFP/YFP pair.

\section{Measuring the FRESCA response in HEK293T cells}

We first tested the selectivity of FRESCA in HEK293T cells, which express negligible

16 levels of CaMKII. We transfected HEK293T cells with either (i) CaMKII, calmodulin and FRESCA, or (ii) calmodulin and FRESCA. Ionomycin was added to the HEK293T

18 cells to induce $\mathrm{Ca}^{2+}$ release and simultaneously monitored FRET (CFP/YFP ratio). We observed that with CaMKII present, the addition of ionomycin causes a reduction in

20 FRET, indicating that CaMKII is active and phosphorylating FRESCA (Fig. 2B, red lines). Importantly, we did not observe a FRET change when CaMKII was not co-

22 transfected, demonstrating that FRESCA is selective for CaMKII and not being phosphorylated by other HEK cell kinases (Fig. 2B, blue lines). 
A

FRESCA: FRET sensor for CaMKII Activity
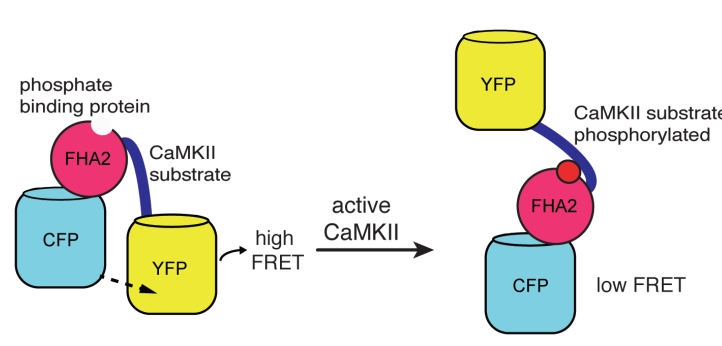

C

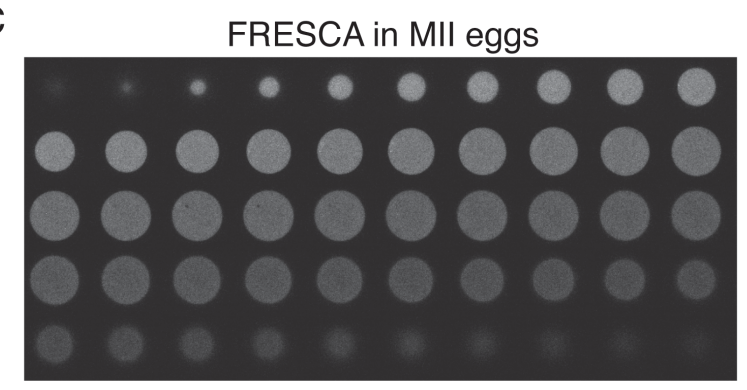

D

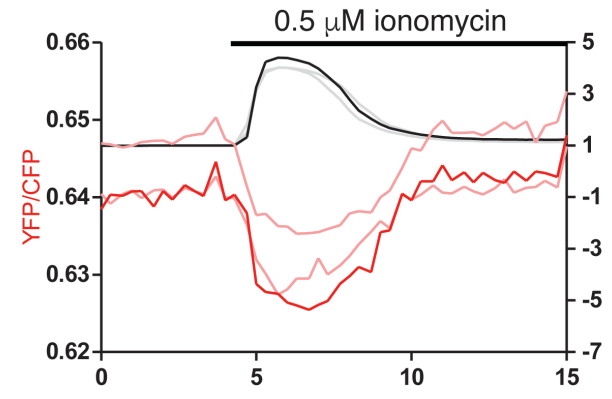

F

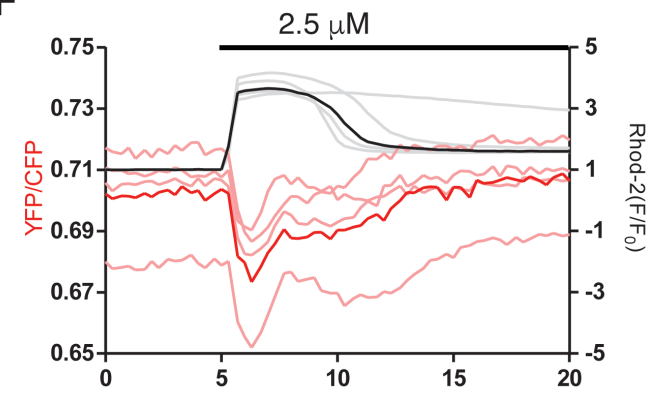

$\mathrm{H}$

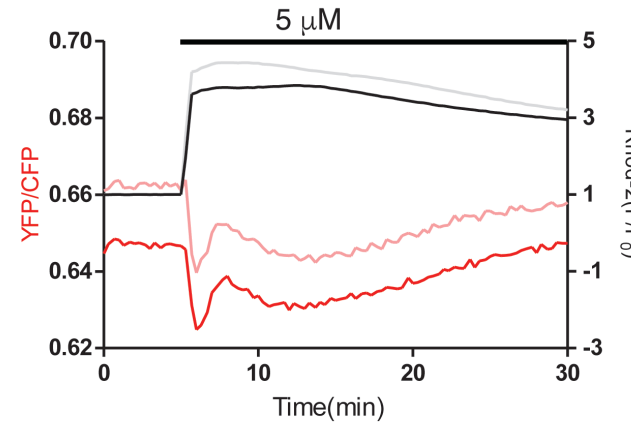

E

G

I
B

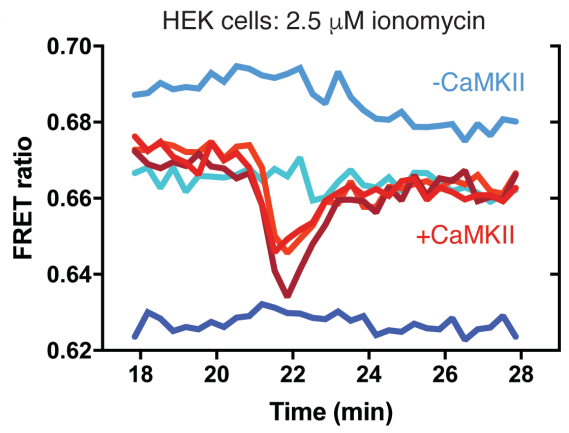

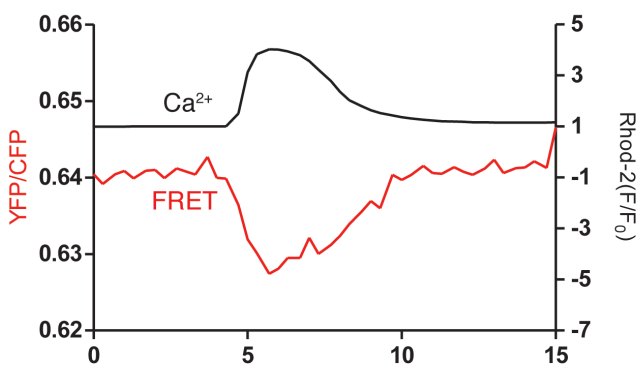
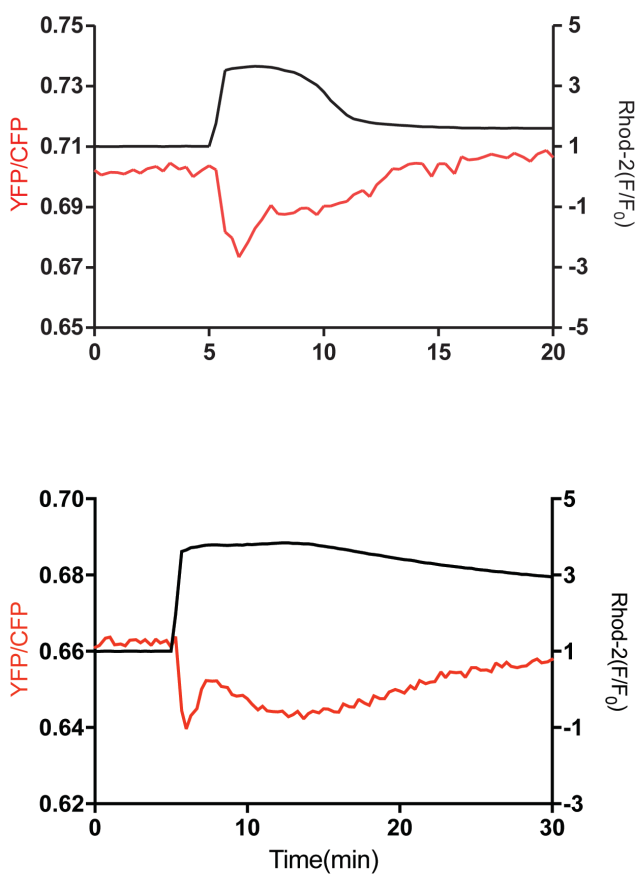
Figure 2. Monitoring endogenous CaMKII activity using FRESCA. A) A cartoon of a substrate-based CaMKII biosensor is shown: FRET Sensor for CaMKII Activity (FRESCA). Active CaMKII phosphorylates its substrate (syntide), which then acts as a substrate for FHA2 (phosphate binding domain). This induces a conformational change in the sensor as a consequence of CaMKII activity. B) FRESCA is transfected into HEK293 cells with and without CaMKII. Ionomycin $(2.5 \mu \mathrm{M})$ is added to induce $\mathrm{Ca}^{2+}$ entry and FRET is monitored as YFP/CFP ratio. Without CaMKII transfected, there is no FRET change visualized. C) FRESCA expression in mouse MII eggs shows a widespread cytoplasmic distribution. D) $\mathrm{Ca}^{2+}$ is monitored using rhod-2 (black) and CaMKII activity

10 is monitored using FRESCA (red). Multiple traces are shown after $0.5 \mu \mathrm{M}$ ionomycin is added. E) One representative trace is shown after addition of $0.5 \mu \mathrm{M}$ ionomycin. F)

12 Multiple traces are shown after $2.5 \mu \mathrm{M}$ ionomycin is added. G) One representative trace is shown after addition of $2.5 \mu \mathrm{M}$ ionomycin. H) Multiple traces are shown after $5 \mu \mathrm{M}$

14 ionomycin is added. I) One representative trace is shown after addition of $5 \mu \mathrm{M}$ ionomycin.

FRESCA in GV oocytes

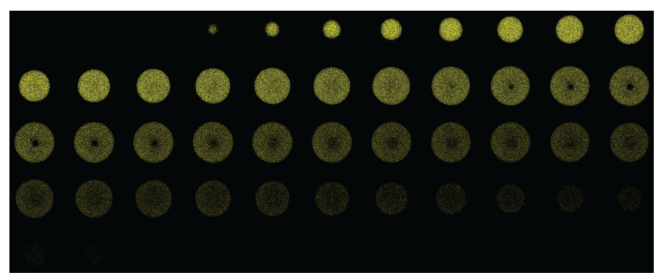

18 Figure 2 - figure supplement 1. FRESCA expression in GV oocytes. Expression is mostly cytoplasmic, as well as some limited nuclear expression.
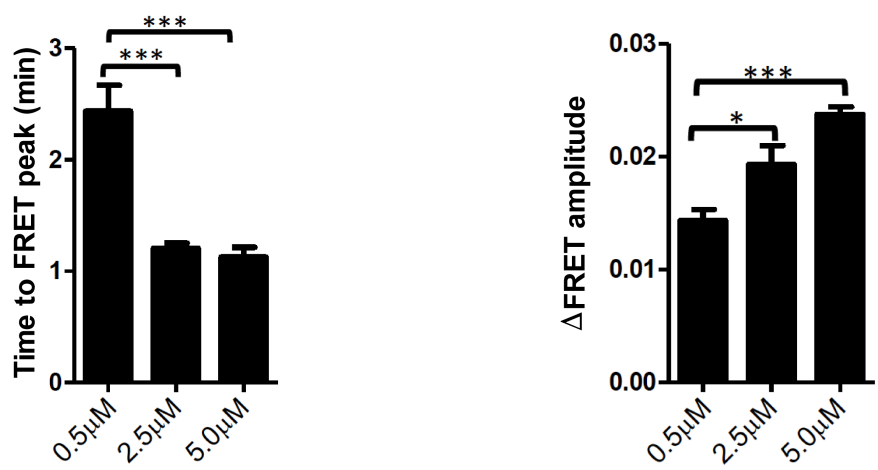

\begin{tabular}{|c|c|c|c|}
\hline & $0.5 \mu \mathrm{M}$ & $2.5 \mu \mathrm{M}$ & $5.0 \mu \mathrm{M}$ \\
\hline Mean & 2.348 & 1.206 & 1.125 \\
\hline Std. Deviation & 0.7191 & 0.1806 & 0.2480 \\
\hline Std. Error & 0.1608 & 0.04516 & 0.08768 \\
\hline
\end{tabular}

\begin{tabular}{|c|c|c|c|}
\hline & $0.5 \mu \mathrm{M}$ & $2.5 \mu \mathrm{M}$ & $5.0 \mu \mathrm{M}$ \\
\hline Mean & 0.0143 & 0.0193 & 0.0237 \\
\hline Std. Deviation & 0.00508 & 0.00671 & 0.00176 \\
\hline Std. Error & 0.00102 & 0.00168 & 0.000665 \\
\hline
\end{tabular}

Figure 2 - figure supplement 2. Quantification of FRESCA response to ionomycin

24 addition. Time to FRET peak indicates how long it takes FRESCA to reach maximum $\triangle$ FRET signal after addition of ionomycin and increase in $\mathrm{Ca}^{2+} . \Delta$ FRET amplitude 
indicates the overall change in FRET during the duration of the $\mathrm{Ca}^{2+}$ signal. Statistics are reported in the tables below, differences were considered significant at $\mathrm{P}<0.05$ (*). $^{*}$.

A

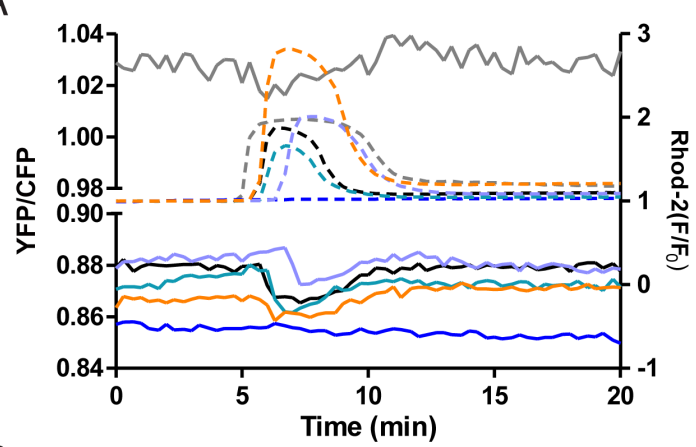

B

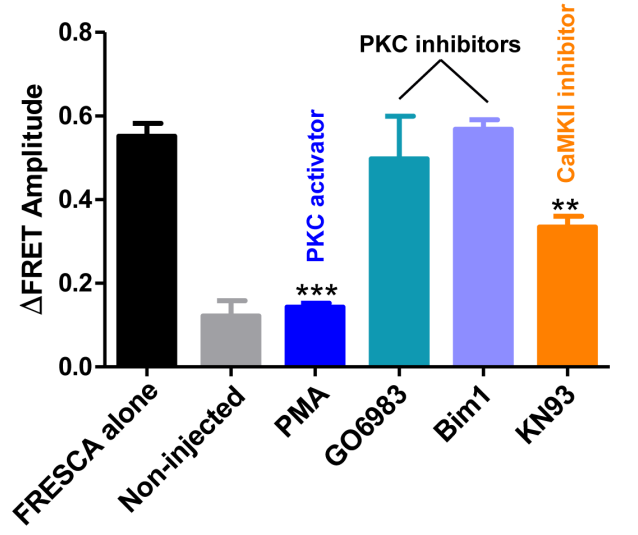

C

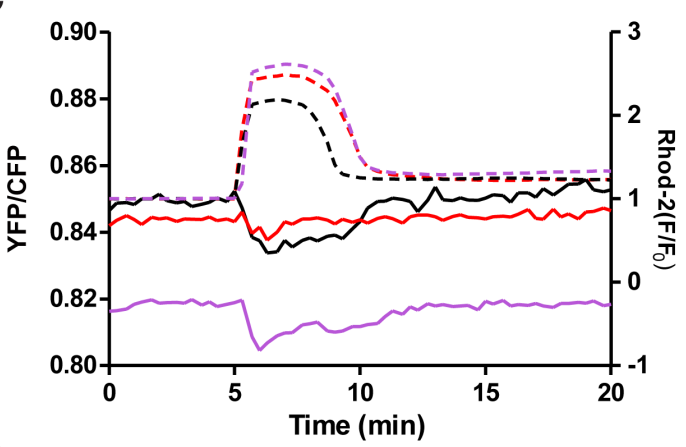

D

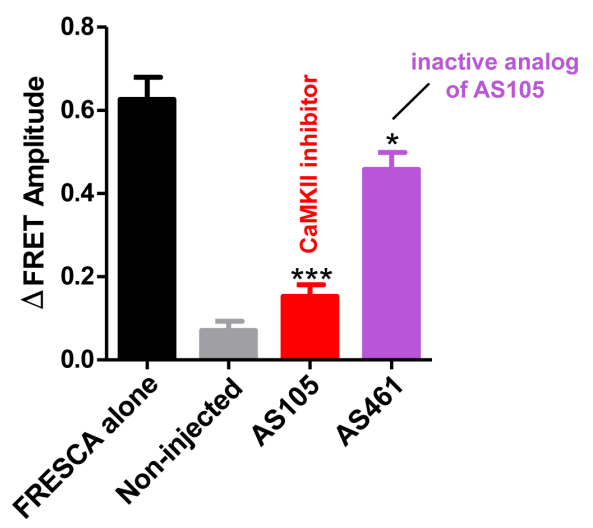

Figure 2 - figure supplement 3. Pharmacological tests of FRESCA specificity in mouse eggs. Various compounds were added to mouse eggs expressing FRESCA. $\mathrm{Ca}^{2+}$ was monitored using Rhod-2 and FRET was monitored by YFP/CFP ratio. A) CaMKII inhibitor: KN93 (0.5 $\mu \mathrm{M})$, PKC inhibitors: GO6983 (3 $\mu \mathrm{M})$ and Bim1 $(5 \mu \mathrm{M})$, and a PKC activator: PMA $(1 \mu \mathrm{M})$ were added to mouse eggs and stimulated with $0.5 \mu \mathrm{M}$ ionomycin. These were directly compared to FRESCA alone and a non-injected control

12 with $0.5 \mu \mathrm{M}$ ionomycin. Colors correspond to the bar graph in (B). B) Quantification of the amplitude of FRET signal in (A). C) CaMKII inhibitor: AS105 (5 $\mu \mathrm{M})$ and inactive

14 analog of this inhibitor: AS461 $(5 \mu \mathrm{M})$ were added to mouse eggs and stimulated with $2.5 \mu \mathrm{M}$ ionomycin. These were directly compared to FRESCA alone and a non-injected

16 control with $2.5 \mu \mathrm{M}$ ionomycin. Colors correspond to the bar graph in (D). D) Quantification of the amplitude of FRET signal in (C). Differences were considered

18 significant at $\mathrm{P}<0.05(*)$.

Using FRESCA to monitor CaMKII activity in mouse eggs

HEK293T cells provided a good model for a highly controlled evaluation of CaMKII

22 activity and the ability of FRESCA to specifically report on CaMKII in the presence of 
other cellular kinases. However, we wanted to test FRESCA in a more complex and

2 native system, importantly, with endogenous $\mathrm{CaMKII}$ and where the $\mathrm{Ca}^{2+}$ response has a clear physiological function. To accomplish this, we expressed FRESCA in mouse eggs

4 to measure endogenous CaMKII $\gamma$ activity following increases in intracellular $\mathrm{Ca}^{2+}$ induced by a variety of agonists.

6

In all mammals, $\mathrm{Ca}^{2+}$ oscillations are required for initiation of embryogenesis (Deguchi,

8 Shirakawa, Oda, Mohri, \& Miyazaki, 2000; Fissore, Dobrinsky, Balise, Duby, \& Robl, 1992). Mammalian eggs are arrested at metaphase II of meiosis; both $\mathrm{Ca}^{2+}$ oscillations

10 and consequent CaMKII activity are required for release from this arrest (Fig. 1D) (Backs et al., 2010; Chang, Minahan, Merriman, \& Jones, 2009; Miao, Stein, Jefferson, Padilla-

12 Banks, \& Williams, 2012; Miyazaki et al., 1992; Presler et al., 2017). $\mathrm{Ca}^{2+}$ oscillations are induced following gamete fusion when the sperm releases into the egg a sperm

14 specific protein (PLCzeta; $\zeta$ ), which triggers the $\mathrm{Ca}^{2+}$ responses (Ducibella et al., 2002; Saunders et al., 2002). On average, there is one $\mathrm{Ca}^{2+}$ rise every 20 minutes and

16 oscillations in mouse zygotes last for $\sim 4$ hours, which coincides with the formation of the pronuclei (PN) (Jones, Carroll, Merriman, Whittingham, \& Kono, 1995). The source of

18 this $\mathrm{Ca}^{2+}$ is from internal stores, which are replenished by $\mathrm{Ca}^{2+}$ influx from the extracellular media. CaMKII is activated simultaneously with the initiation of $\mathrm{Ca}^{2+}$

20 oscillations and female mice that are CaMKII $\gamma$ null are sterile (Backs et al., 2009). Despite the role of CaMKII $\gamma$ in the initiation of development, the complete profile of

22 CaMKII activity during fertilization in mammals is not known. Further, CaMKII activity also seems to play a role in preventing apoptosis in Xenopus and mouse eggs, although 
the pattern and degree of activation for this activity are even less studied (Nutt et al.,

2 2005).

4 To date, CaMKII activity has only been assessed based on a few $\mathrm{Ca}^{2+}$ rises using in vitro kinase assays and during only the first hour of oscillations, which is considerably shorter

6 than the time scale for normal oscillations in the mouse. Therefore, there is a need to monitor CaMKII activity in live cells and for an extended time, which is what we address

8 here.

10 FRESCA and ionomycin-induced $\mathrm{Ca}^{2+}$ oscillations in mouse eggs

FRESCA expression and distribution in germinal vesicle $(\mathrm{GV})$ oocytes and MII stage

12 oocytes, henceforth referred to as eggs, was widespread and cytoplasmic (Fig. 2C). However, a small amount of FRESCA appeared to enter the nucleus of GV oocytes (Fig.

\section{2 , supplement 1).}

16 Given the immediate and large $\mathrm{Ca}^{2+}$ rise caused by the addition of ionomycin, we first tested FRESCA responses in eggs using this ionophore. We analyzed the effect of 3

18 concentrations of ionomycin: $0.5 \mu \mathrm{M}, 2.5 \mu \mathrm{M}$ and $5 \mu \mathrm{M}$. Upon addition of ionomycin to eggs expressing FRESCA, we observed a FRET decrease, indicating CaMKII activity

20 (Fig. 2D-I). At the lowest ionomycin concentration $(0.5 \mu \mathrm{M})$, CaMKII activity appears to perfectly track the $\mathrm{Ca}^{2+}$ pulse (Fig. 2D, E). Conversely, at higher ionomycin

22 concentrations, CaMKII activity is unstable during the duration of the $\mathrm{Ca}^{2+}$ pulse, although higher concentrations appeared to prolong and increase the FRET response of 
FRESCA (Fig. 2, supplement 2). The time to FRET peak was faster with addition of

2 higher ionomycin concentrations (Fig. 2, supplement 2).

4 We tested the specificity of FRESCA for CaMKII in mouse eggs. We first used CaMKII inhibitors, which should eliminate the FRET response if CaMKII is the only kinase

6 phosphorylating FRESCA in eggs (Fig. 2, supplement 3). We show that the addition of KN93, a commonly used allosteric inhibitor for CaMKII, significantly reduces FRET

8 (Madgwick, Levasseur, \& Jones, 2005; Smyth et al., 2002). Addition of AS105, an ATP competitive CaMKII specific inhibitor, also significantly reduces FRET, while its

10 inactive analog (AS461) does not affect FRET (Neef et al., 2018). We also tested inhibition and activation of protein kinase $\mathrm{C}(\mathrm{PKC})$, since $\mathrm{PKC}$ is the other major $\mathrm{Ca}^{2+}$

12 sensitive kinase in mouse eggs (Medvedev, Stein, \& Schultz, 2014; Wang et al., 2010). Addition of PKC inhibitors Bim1 (Halet, 2004) and GO6983 (Gou, Wang, Zou, Qi, \&

$14 \mathrm{Xu}, 2018$ ) do not affect the FRESCA signal, indicating that PKC is not phosphorylating FRESCA. Eggs do not express conventional PKC isoforms, so the results of the broad16 spectrum PKC inhibitor (GO6983) reinforced the results of Bim1. Finally, addition of PMA, a PKC activator shown to stimulate this enzyme in mouse eggs (Halet, 2004), also

18 does not induce FRET (Fig. 2, supplement 3). Taken together, we report that FRESCA is a specific reporter of CaMKII activity in mouse eggs. 

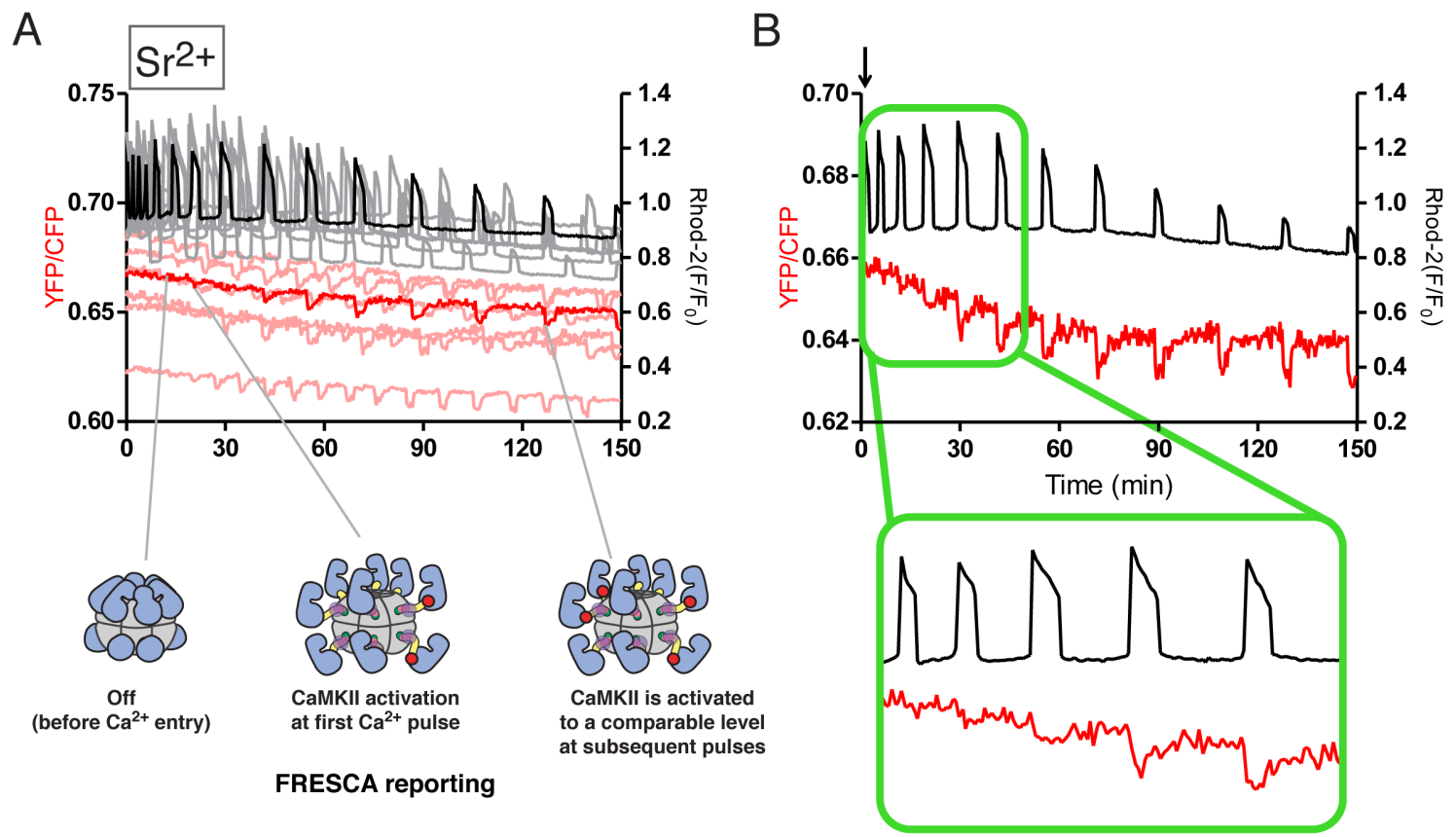

Figure 3. Endogenous CaMKII activity tracks $\mathrm{Ca}^{2+}$ oscillations in mouse eggs. A) $\mathrm{Ca}^{2+}$ oscillations in eggs are induced by addition of $\mathrm{Sr}^{2+}$ to the extracellular media. $\mathrm{Ca}^{2+}$ is monitored by Rhod-2 (black line) and endogenous CaMKII activity is tracked by FRESCA (red line). B) One representative trace from $\mathrm{Sr}^{2+}$ oscillations is shown. Inset focuses on the first $\mathrm{Ca}^{2+}$ rises. 

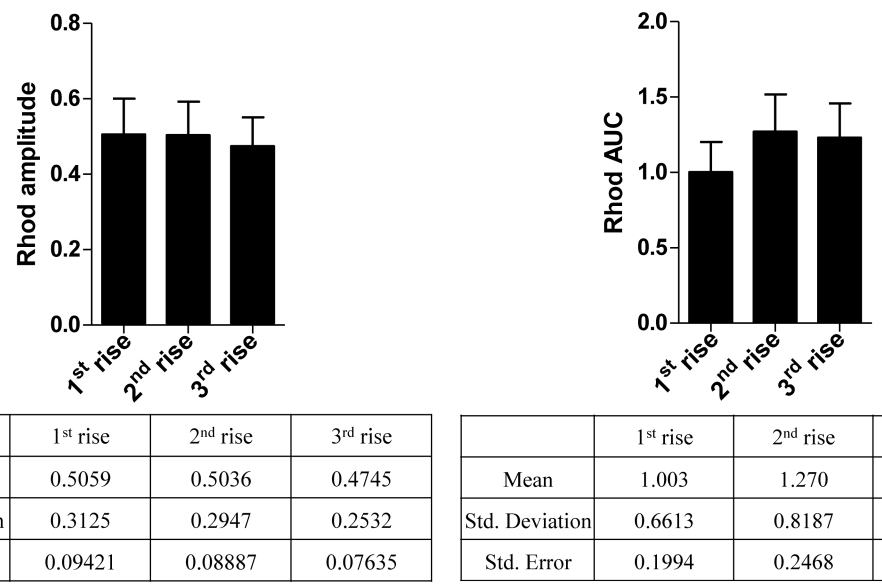

\begin{tabular}{|c|c|c|c|}
\hline & $1^{\text {st }}$ rise & $2^{\text {nd }}$ rise & $3^{\text {rd }}$ rise \\
\hline Mean & 0.5059 & 0.5036 & 0.4745 \\
\hline Std. Deviation & 0.3125 & 0.2947 & 0.2532 \\
\hline Std. Error & 0.09421 & 0.08887 & 0.07635 \\
\hline
\end{tabular}

\begin{tabular}{|c|c|c|c|}
\hline & $1^{\text {st }}$ rise & $2^{\text {nd }}$ rise & $3^{\text {rd }}$ rise \\
\hline Mean & 1.003 & 1.270 & 1.230 \\
\hline Std. Deviation & 0.6613 & 0.8187 & 0.7511 \\
\hline Std. Error & 0.1994 & 0.2468 & 0.2265 \\
\hline
\end{tabular}

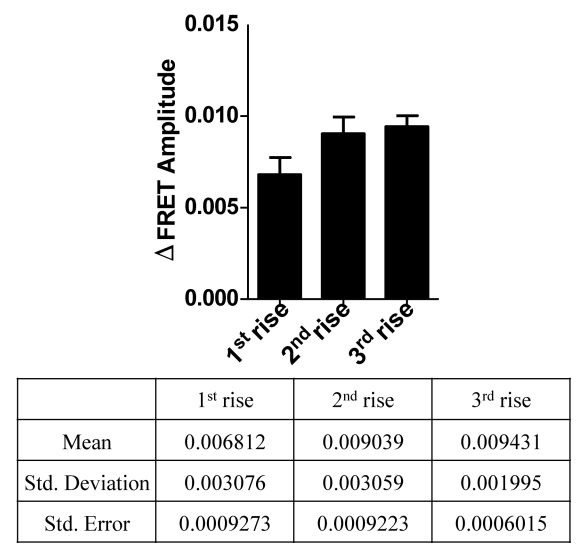

Figure 3 - figure supplement 1. Quantification of Rhod-2 and FRET signals for

4 FRESCA during $\mathrm{Sr}^{2+}$ induced oscillations. Three $\mathrm{Ca}^{2+}$ rises were quantified. The " 1 st rise" is that which induced the first FRET response, and then the subsequent 2 rises were measured. Statistics are reported in the tables below, differences were considered significant at $\mathrm{P}<0.05$ (*).

8

10

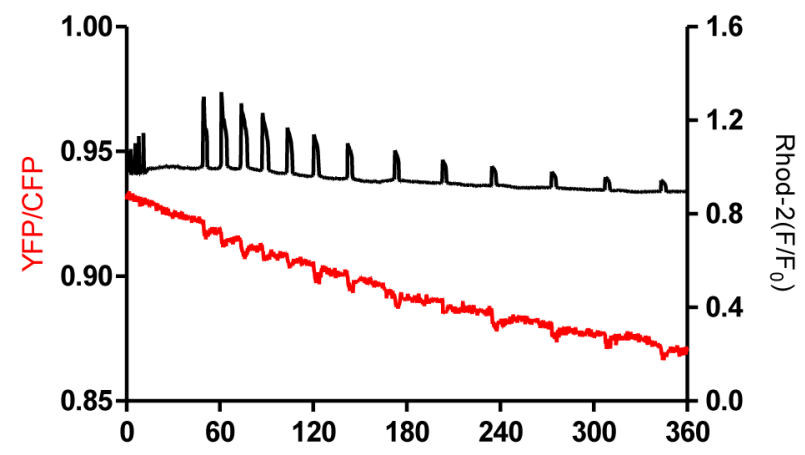


Figure 3 - figure supplement 2. Increased time course of FRESCA response to $\mathrm{Sr}^{2+}$.

$2 \mathrm{Sr}^{2+}(10 \mathrm{mM})$ was added to mouse eggs expressing FRESCA. $\mathrm{Ca}^{2+}$ is monitored by Rhod2 (black line) and endogenous CaMKII activity is tracked by FRESCA (red line) for 6

4 hours. The progressive decreasing amplitude of the Rhod-2 AM fluorescence signal (especially after $180 \mathrm{~min}$ ) is an artifact due to compartmentalization of the dye due to

6 prolonged monitoring at $>35^{\circ} \mathrm{C}$.

8 FRESCA and $\mathrm{Sr}^{2+}$-induced $\mathrm{Ca}^{2+}$ oscillations

Addition of $10 \mathrm{mM} \mathrm{Sr}^{2+}$ to the extracellular media in place of external $\mathrm{Ca}^{2+}$ is a common

10 method of parthenogenetic activation in mouse eggs, and it induces highly consistent oscillations in these cells (Fig. 3, black lines); these oscillations initiate all events of egg

12 activation (Bosmikich \& Whittingham, 1995; Carvacho, Lee, Fissore, \& Clapham, 2013; Kline \& Kline, 1992). Further, the TRPV3 channel has recently been identified as the

14 channel responsible for $\mathrm{Sr}^{2+}$ influx in mouse eggs (Carvacho et al., 2013). We therefore examined the response of endogenous CaMKII to $\mathrm{Sr}^{2+}$-induced oscillations. We observed

16 endogenous CaMKII $\gamma$ activity (monitored by FRESCA) almost simultaneously with the initiation of oscillations. Indeed, nearly all eggs (11/13) showed CaMKII activity within

18 the first two rises. Importantly, CaMKII activity is reproduced over time, as FRESCA continues to track each $\mathrm{Ca}^{2+}$ rise for $>2$ hours (Fig. 3B).

We propose a molecular model to describe this data. The $\mathrm{Ca}^{2+}$ rises progressively

22 decrease in duration/amplitude over time (Deguchi et al., 2000), however, the FRESCA responses are not diminished and the peak kinase activity seems to outlast the peak

24 elevation of $\mathrm{Ca}^{2+} / \mathrm{Sr}^{2+}$. This suggests autophosphorylation of CaMKII at $\mathrm{Thr} 286$, which facilitates activation at subsequent $\mathrm{Ca}^{2+}$ pulses by increasing the affinity for $\mathrm{Ca}^{2+} / \mathrm{CaM}$

26 (see cartoons in Fig. 3A) (Meyer, Hanson, Stryer, \& Schulman, 1992). Additionally, a 
prolonged time course of FRESCA response to $\mathrm{Sr}^{2+}$ indicates that FRESCA continues to

2 faithfully track endogenous CaMKII up to 6 hours (Fig. 3, supplement 2).

\section{$4 \quad$ Using Camui to measure CaMKII activity in mouse eggs}

As described, the highly used Camui biosensor is comprised of CaMKII itself (see Fig.

6 4A), specifically CaMKII , which has a 30-residue variable linker region (Fig. 4C).

Despite its widespread use, Camui has not yet been used to monitor CaMKII activity in

8 mouse eggs. Given that it has been demonstrated that CaMKII activity is tuned by the length of the variable linker (Bayer et al., 2002; Chao et al., 2011), specifically, as the

10 variable linker is lengthened, less $\mathrm{Ca}^{2+}$ is needed for activation, we hypothesized that FRESCA may report CaMKII activity in mouse eggs more faithfully than Camui. This

12 assumption is based on the knowledge that mouse eggs express equimolar concentrations of the two versions of CaMKII $\gamma(\gamma 3$ and $\gamma \mathrm{J})$, which have 69 and 90 residue variable

14 linkers, respectively (Fig. 4C) (Hatch \& Capco, 2001; Suzuki, Hara, Takagi, Yamamoto, \& Ueno, 2011), considerably longer than the 30-residue linker of CaMKII $\alpha$. We therefore

16 tested the response of Camui compared to FRESCA.

18 We expressed the Camui reporter in mouse eggs using mRNA injection, and similar to FRESCA, expression was robust within $\sim 30$ minutes and we began FRET measurements

$20 \sim 4$ hours post injection to attain stable Camui levels. As shown by confocal microscopy, Camui attained a widespread cytoplasmic expression in eggs, although in GVs it was

22 excluded from the nucleus, which is consistent with the reported expression of CaMKII in the cytosol of mouse eggs (Fig. 4B and Fig 4., supplement 1) (Hatch \& Capco, 2001). 
A

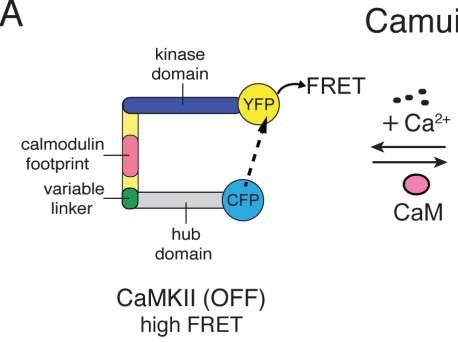

Camui

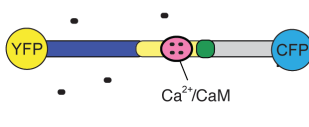

CaM-bound CaMKII (ON) low FRET
B

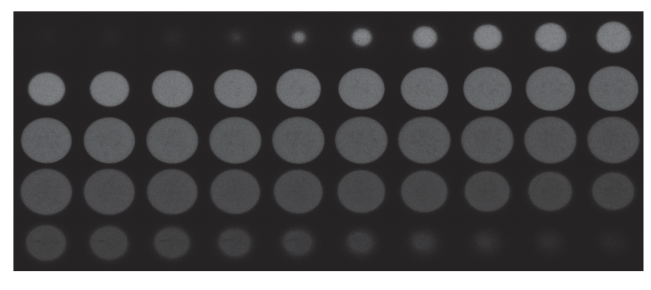

C

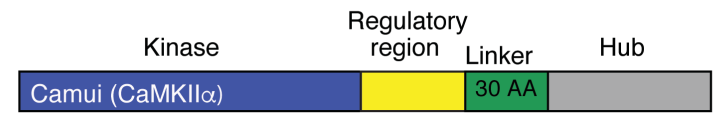

\begin{tabular}{|l|l|l|l|}
\hline CaMKIly3 & & $69 \mathrm{AA}$ & \\
\hline
\end{tabular}

CaMKIIrJ

$90 \mathrm{AA}$

D

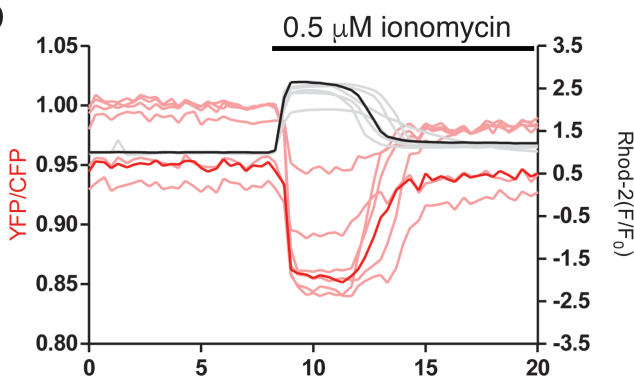

F

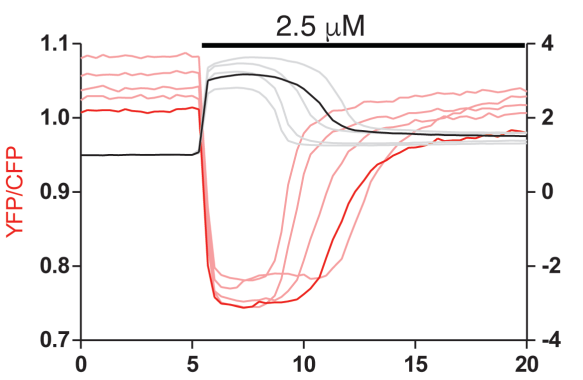

$\mathrm{H}$

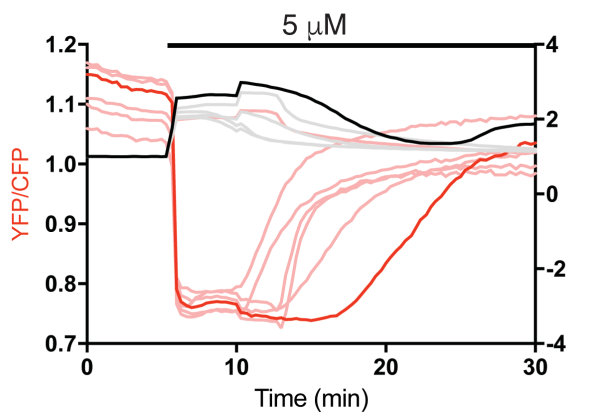

E

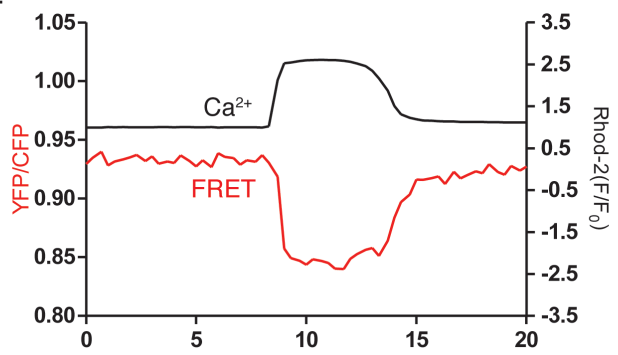

G
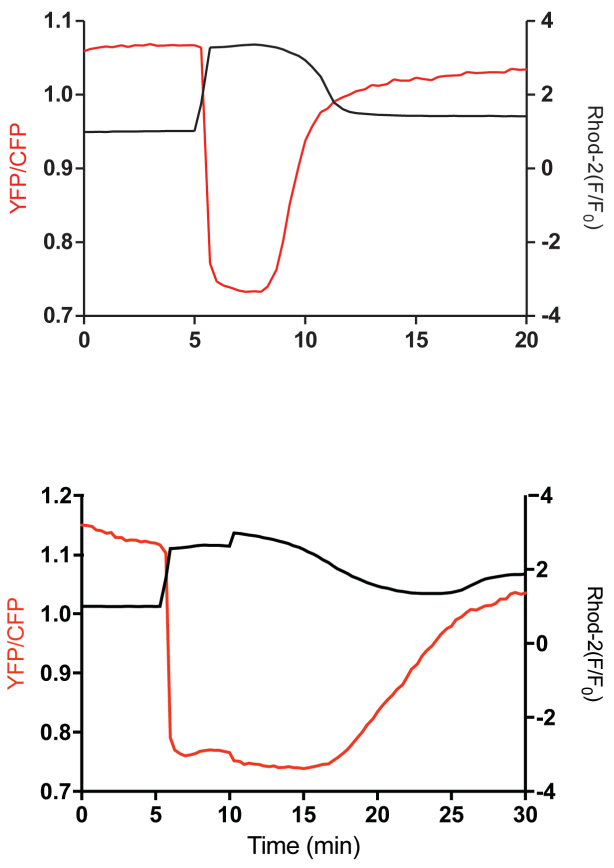
Figure 4. Simultaneously monitoring $\mathrm{Ca}^{2+}$ influx and CaMKII activity using Camui.

2 A) Camui is an existing biosensor for CaMKII activity, which exploits the conformational change of CaMKII binding to $\mathrm{Ca}^{2+} / \mathrm{CaM}$ to report on activity using FRET. B) Camui expression in mouse MII eggs shows a widespread cytoplasmic distribution. C) Linear sequences of Camui (CaMKII $\alpha$ ), and the two CaMKII isoforms

6 reported in eggs (CaMKII $\gamma 3$ and $\gamma \mathrm{J})$. D) Changes in $\mathrm{Ca}^{2+}$ are monitored using rhod-2 (black) and CaMKII activity is monitored using Camui (red). Multiple traces are shown

8 after $0.5 \mu \mathrm{M}$ ionomycin is added. E) One representative trace is shown after addition of $0.5 \mu \mathrm{M}$ ionomycin. F) Multiple traces are shown after $2.5 \mu \mathrm{M}$ ionomycin is added. $\mathrm{G}$ )

10 One representative trace is shown after addition of $2.5 \mu \mathrm{M}$ ionomycin. $\mathrm{H}$ ) Multiple traces are shown after $5 \mu \mathrm{M}$ ionomycin is added. I) One representative trace is shown after

12 addition of $5 \mu \mathrm{M}$ ionomycin. Camui in GV oocytes

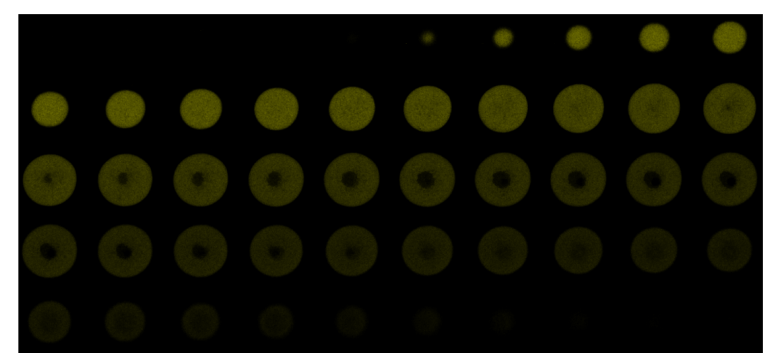

14 Figure 4 - figure supplement 1. Camui expression in GV oocytes. Expression is mostly cytoplasmic, and is excluded from the nucleus.
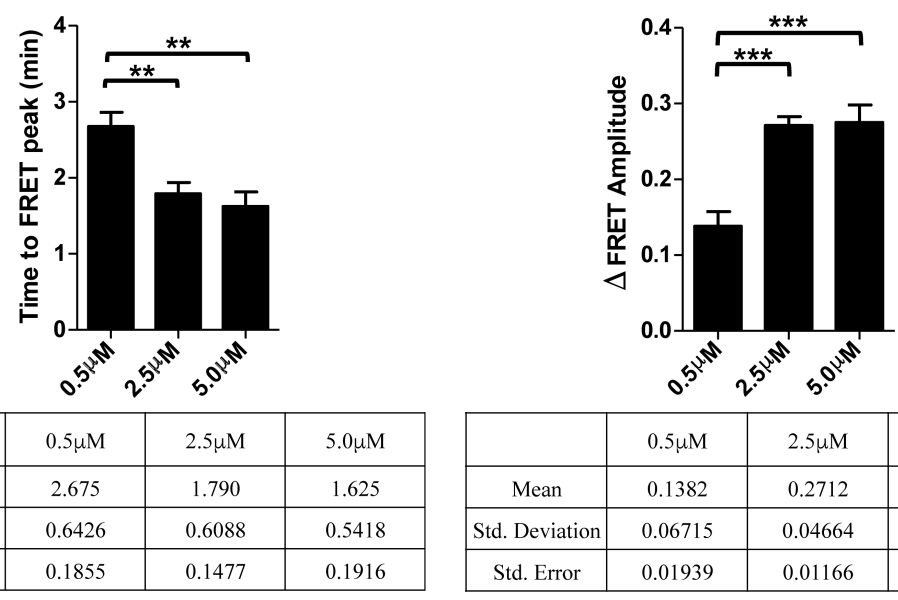

\begin{tabular}{|c|c|c|c|}
\hline & $0.5 \mu \mathrm{M}$ & $2.5 \mu \mathrm{M}$ & $5.0 \mu \mathrm{M}$ \\
\hline Mean & 2.675 & 1.790 & 1.625 \\
\hline Std. Deviation & 0.6426 & 0.6088 & 0.5418 \\
\hline Std. Error & 0.1855 & 0.1477 & 0.1916 \\
\hline
\end{tabular}

\begin{tabular}{|c|c|c|c|}
\hline & $0.5 \mu \mathrm{M}$ & $2.5 \mu \mathrm{M}$ & $5.0 \mu \mathrm{M}$ \\
\hline Mean & 0.1382 & 0.2712 & 0.2750 \\
\hline Std. Deviation & 0.06715 & 0.04664 & 0.06573 \\
\hline Std. Error & 0.01939 & 0.01166 & 0.02324 \\
\hline
\end{tabular}

18 Figure 4 - figure supplement 2. Quantification of Camui response to ionomycin addition. Time to FRET peak indicates how long it takes FRESCA to reach maximum

$20 \Delta$ FRET signal after addition of ionomycin and increase in $\mathrm{Ca}^{2+} . \Delta \mathrm{FRET}$ amplitude indicates the overall change in FRET during the duration of the $\mathrm{Ca}^{2+}$ signal. Statistics are

22 reported in the tables below, differences were considered significant at $\mathrm{P}<0.05\left(^{*}\right)$. 


\section{Camui and ionomycin-induced $\mathrm{Ca}^{2+}$ oscillations}

2 We first induced $\mathrm{Ca}^{2+}$ release in eggs by adding ionomycin as previously described and simultaneously monitored changes in FRET values (YFP/CFP) (Fig. 4C-H). As with

4 FRESCA, a decrease in FRET is indicative of an increase in CaMKII activity. It is clear that CaMKII activity increases (red line) coincident with the increase in $\mathrm{Ca}^{2+}$ (black line)

6 in all conditions. The $\mathrm{Ca}^{2+}$ and Camui responses increased dose-dependently and approximately synchronously, as the large increase in the amount of $\mathrm{Ca}^{2+}$ release caused

8 by increasing ionomycin from $0.5 \mu \mathrm{M}$ to $2.5 \mu \mathrm{M}$, results in a 1.9-fold increase in CaMKII activity (mean amplitude of FRET change) (Fig. 4, supplement 2). Further

10 increasing ionomycin from $2.5 \mu \mathrm{M}$ to $5 \mu \mathrm{M}$ produces nearly no change in total $\mathrm{Ca}^{2+}$ release, although it is very likely that the reporting range of Rhod-2 is saturated at these

12 levels of $\mathrm{Ca}^{2+}$ release. The CaMKII activity also appears to remain constant, although this may also represent saturation of the FRET signal (Fig. 4, supplement 2). Notably,

14 addition of $5 \mu \mathrm{M}$ ionomycin results in a prolonged duration of activity compared to lower concentrations, but it is unclear whether this reflects the extended activation of the

16 enzyme or cellular stress.

18 The absolute amplitude of the change in the FRET ratio for Camui after the addition of $0.5 \mu \mathrm{M}$ ionomycin is $\sim 10$-fold greater than what is observed for FRESCA $(0.014$ for

20 FRESCA compared to 0.14 for Camui), however, this measurable signal change in FRESCA is sufficient to monitor endogenous CaMKII $\gamma$ activity, which we cannot detect

22 with Camui, which reports CaMKII $\alpha$ activity. In addition, it is worth noting that the shape of the FRESCA traces is slightly different from those of Camui for the same 
stimulus. The peak activity of FRESCA is shorter than the corresponding $\mathrm{Ca}^{2+}$ peak,

2 although the return to basal activity is more protracted, whereas the Camui response more perfectly tracks the shape of the $\mathrm{Ca}^{2+}$ peak.
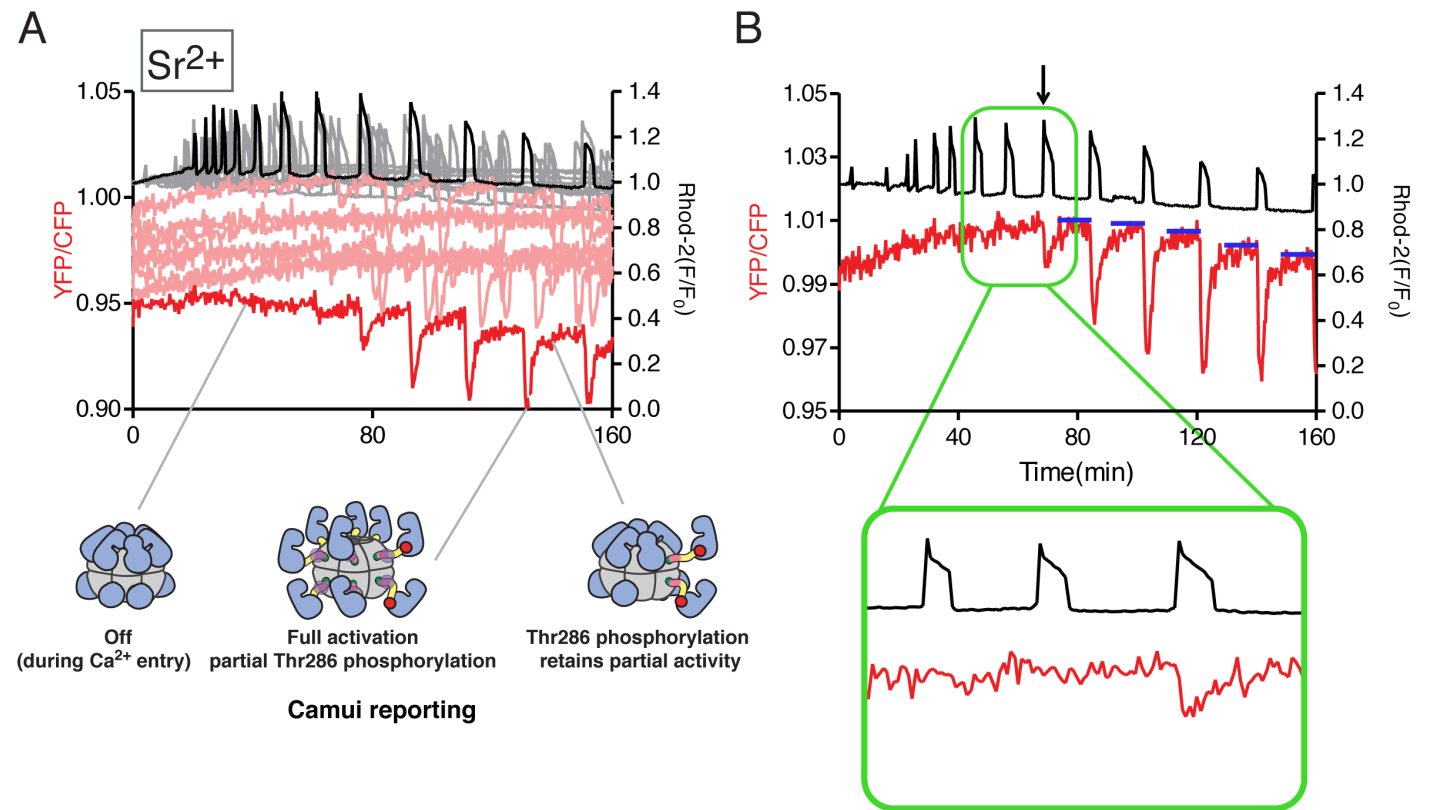

Figure 5. Camui activity tracks $\mathrm{Ca}^{2+}$ oscillations in mouse eggs in a delayed manner. A) $\mathrm{Ca}^{2+}$ oscillations are induced by addition of $\mathrm{Sr}^{2+} \cdot \mathrm{Ca}^{2+}$ is monitored by Rhod-2 (black line) and CaMKII activity is tracked by Camui (red line). CaMKII cartoons indicate hypothesized molecular details during the $\mathrm{Ca}^{2+}$ pulses. B) One representative trace from $\mathrm{Sr}^{2+}$ oscillations is shown. Blue lines indicate baseline CaMKII activity after each rise. Arrow indicates first significant FRET response. 

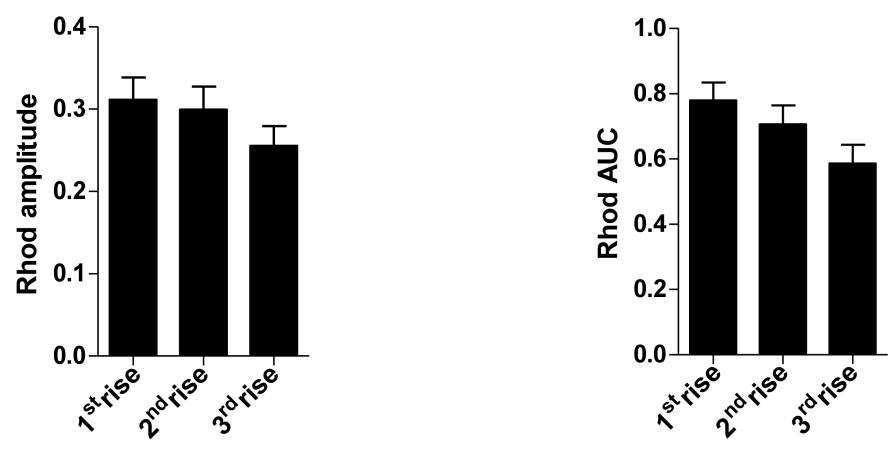

\begin{tabular}{|c|c|c|c|}
\hline & $1^{\text {st }}$ rise & $2^{\text {nd }}$ rise & $3^{\text {rd }}$ rise \\
\hline Mean & 0.3115 & 0.2994 & 0.2556 \\
\hline Std. Deviation & 0.1048 & 0.1046 & 0.09001 \\
\hline Std. Error & 0.02706 & 0.02796 & 0.02406 \\
\hline
\end{tabular}

\begin{tabular}{|c|c|c|c|}
\hline & $1^{\text {st }}$ rise & $2^{\text {nd }}$ rise & $3^{\text {rd }}$ rise \\
\hline Mean & 0.7793 & 0.7063 & 0.5860 \\
\hline Std. Deviation & 0.2128 & 0.2179 & 0.2149 \\
\hline Std. Error & 0.05494 & 0.05822 & 0.05743 \\
\hline
\end{tabular}

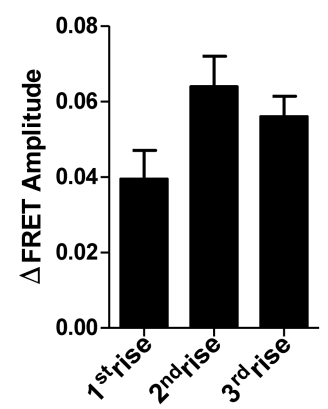

\begin{tabular}{|c|c|c|c|}
\hline & $1^{\text {st }}$ rise & $2^{\text {nd }}$ rise & $3^{\text {rd }}$ rise \\
\hline Mean & 0.03941 & 0.06391 & 0.05598 \\
\hline Std. Deviation & 0.02954 & 0.03024 & 0.02020 \\
\hline Std. Error & 0.007627 & 0.008082 & 0.005400 \\
\hline
\end{tabular}

2 Figure 5 - figure supplement 1. Quantification of Rhod-2 and FRET signals for Camui during $\mathrm{Sr}^{2+}$ induced oscillations. Three $\mathrm{Ca}^{2+}$ rises were quantified. The " 1 st rise"

4 is that which induced the first FRET response, and then the subsequent 2 rises were measured. Statistics are reported in the tables below, differences were considered

6 significant at $\mathrm{P}<0.05(*)$.

8 Camui and $\mathrm{Sr}^{2+}$ induced $\mathrm{Ca}^{2+}$ oscillations

We next examined the Camui response to $\mathrm{Sr}^{2+}$-induced oscillations (Fig. 5). Remarkably,

10 despite the presence of robust changes in intracellular $\mathrm{Ca}^{2+}$ levels, Camui (Fig. 5, red line) did not report any CaMKII activity until the $\sim 6^{\text {th }}$ significant $\mathrm{Ca}^{2+}$ rise (Fig. $5 \mathrm{~B}$,

12 arrow and inset). In total, only $33 \%$ of the eggs expressing Camui showed activity in the first two rises, whereas nearly all FRESCA expressing eggs showed activity within the 14 first two rises. These data suggest that the endogenous CaMKII $\gamma$ in eggs is more sensitive 
to $\mathrm{Ca}^{2+} / \mathrm{CaM}$ than CaMKII $\alpha$. This finding is in line with previous data showing that

2 longer linker CaMKII splice variants (CaMKII $\gamma 3$ and $\mathrm{CaMKII} \gamma \mathrm{J})$ are activated at lower concentrations of $\mathrm{Ca}^{2+} / \mathrm{CaM}$ than shorter linker variants (CaMKII $\alpha$ ) (see Fig. 4C) (Chao

4 et al., 2011). Additionally, the delayed response seen in the Camui eggs could also be a result of endogenous CaMKII being activated first (lower $\mathrm{EC}_{50}$ for $\mathrm{Ca}^{2+} / \mathrm{CaM}$ ) thereby

6 competing with Camui for the available activating ligand.

8 Another distinctive feature of the Camui response caused by $\mathrm{Sr}^{2+}$ oscillations is that whereas the initial Camui responses were delayed, once they commenced, they displayed

10 an integrated activation with each subsequent pulse. For example, we analyzed the mean amplitude for the first three observable FRET changes. From the first to the second FRET

12 change, there was a 1.6-fold increase in CaMKII activity. From the second to the third FRET change, there was a negligible change, and these changed occurred while the

14 amplitude of the $\mathrm{Ca}^{2+}$ peaks progressively decreased and/or remained unchanged (Fig. 5, supplement 1). These data indicate that CaMKII activity, once stimulated, is cooperative

16 with each additional $\mathrm{Ca}^{2+}$ pulse. This result is consistent with previous data showing that CaMKII activity is highly cooperative in vitro (Chao et al., 2010; Chao et al., 2011). As

18 depicted in Figure 5A, a potential explanation for this is phosphorylation at Thr286 which may persist even in the absence of elevated $\mathrm{Ca}^{2+}$. It has been clearly shown that CaMKII

20 with Thr286 phosphorylated has a significantly higher affinity for $\mathrm{Ca}^{2+} / \mathrm{CaM}$ (Meyer et al., 1992). This would also explain why the FRET level does not return to baseline in

22 between later $\mathrm{Ca}^{2+}$ oscillations (Fig. 5B, blue lines). 


\section{Measuring CaMKII activity under native fertilization conditions}

2 In mammals, fertilization-associated $\mathrm{Ca}^{2+}$ oscillations are induced by the release of sperm's PLC $\zeta$ into the ooplasm (Saunders et al., 2002). We tested the response of both

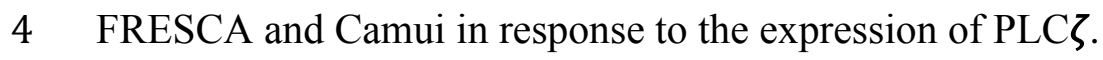

\section{FRESCA and PLC $\zeta$-induced $\mathrm{Ca}^{2+}$ oscillations}

We accomplished PLC $\zeta$ expression by injection of its mRNA into FRESCA expressing

8 eggs, and thereafter began monitoring changes in FRESCA responses (Fig. 6A, B). The initiation of oscillations stimulated the early activity of the endogenous CaMKII $\gamma$, and

10 this activity was detected with each additional rise. Similar to $\mathrm{Sr}^{2+}$ induced oscillations, we observed a relative decrease in the amplitude of the $\mathrm{Ca}^{2+}$ pulses over time, yet the

12 FRESCA response was largely maintained (Fig. 6, supplement 1). These observations are the longest evaluation of CaMKII activity following natural oscillations ever reported

14 following fertilization, as previous studies only reported up to 60 min post-initiation of oscillations (Markoulaki, Matson, \& Ducibella, 2004; Ozil et al., 2005).

\section{Camui and PLC -induced $\mathrm{Ca}^{2+}$ oscillations}

18 We next assessed how Camui would report CaMKII activity induced by $\mathrm{Ca}^{2+}$ oscillations, and compare the response to those induced by $\mathrm{Sr}^{2+}$. To do this, eggs expressing Camui

20 were injected with PLC $\zeta$ mRNA and $\mathrm{Ca}^{2+}$ and FRET responses were monitored. Similar to FRESCA, we observed that $\mathrm{Ca}^{2+}$ oscillations nearly immediately induced CaMKII

22 activity as monitored by Camui (Fig. 6D, arrow and bottom inset). However, this initial 
activity was not detected in subsequent rises, and only the first and second (and to a less

2 extent, third) $\mathrm{Ca}^{2+}$ rises induced Camui responses despite the presence of robust and frequent $\mathrm{Ca}^{2+}$ oscillations (Fig. 6C, D, supplement 2). Additionally, it is worth pointing

4 out that the area under the curve for the third $\mathrm{Ca}^{2+}$ rise in these experiments was significantly reduced. This may be due to the fact that Camui itself is contributing

6 significantly to the existing CaMKII in the egg, and potentially altering $\mathrm{Ca}^{2+}$ dynamics. These results raised the possibility that Camui is not well suited to detect CaMKII

8 activity initiated by sporadic and low magnitude $\mathrm{Ca}^{2+}$ rises, which are characteristic of mammalian fertilization. Regardless, it remains to be elucidated why $\mathrm{Sr}^{2+}$ induced

10 oscillations are able to protractedly promote robust and persistent Camui responses whereas the Camui response to PLC $\zeta$-induced oscillations fades rapidly. 


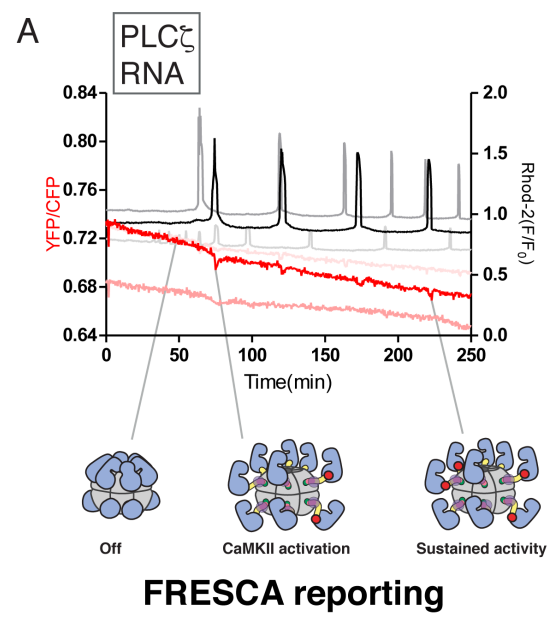

B
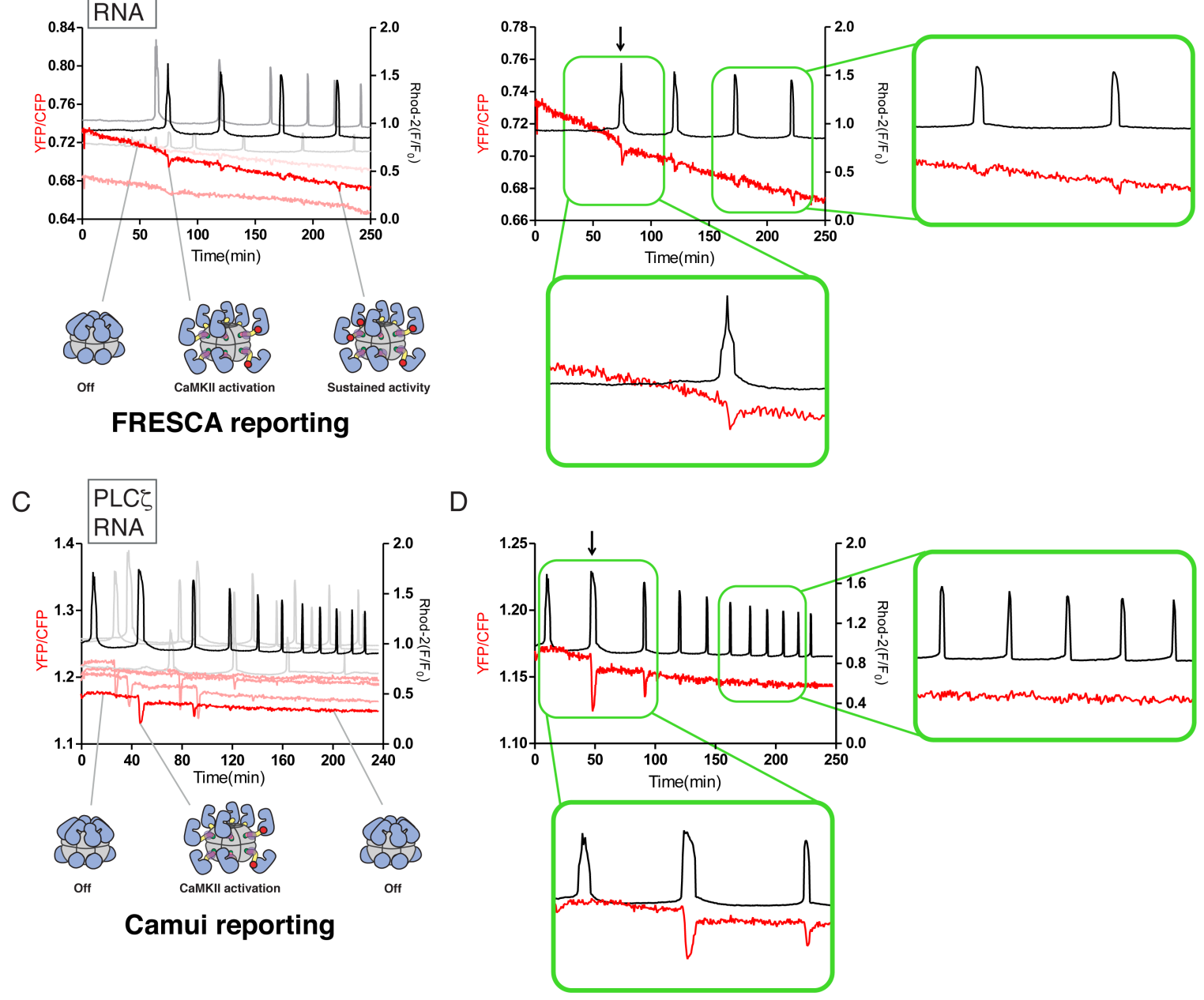

2 Figure 6. FRESCA, but not Camui, continues to report CaMKII activation by $\mathrm{Ca}^{2+}$ oscillations induced by PLC $\zeta$ injection

$4 \mathrm{Ca}^{2+}$ oscillations are induced by injection of PLC $\zeta$ mRNA. CaMKII activity is monitored using FRESCA or Camui (FRET, red lines) and $\mathrm{Ca}^{2+}$ is monitored using

6 Rhod-2 (black lines). A) An overlay of 3 representative eggs using FRESCA as the reporter of endogenous CaMKII activity. Cartoon depictions of hypothesized states of

8 CaMKII are shown below. Red circles indicate Thr286 phosphorylation. B) One representative trace from PLC $\zeta$-induced oscillations and FRESCA reporting is shown.

10 Insets highlight the first and last pulses. C) An overlay of 4 representative eggs using Camui as the reporter of CaMKII $\alpha$ activity. Cartoon depictions of hypothesized states

12 of CaMKII are shown below. Red circles indicate Thr286 phosphorylation. D) One representative trace from PLC $\zeta$-induced oscillations and Camui reporting is shown.

14 Insets highlight the first and last pulses. 


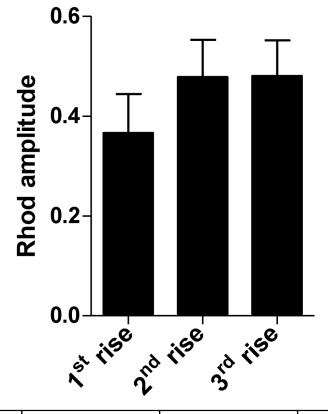

\begin{tabular}{|c|c|c|c|}
\hline & $1^{\text {st }}$ rise & $2^{\text {nd }}$ rise & $3^{\text {rd }}$ rise \\
\hline Mean & 0.3665 & 0.4785 & 0.4803 \\
\hline Std. Deviation & 0.2326 & 0.2224 & 0.1896 \\
\hline Std. Error & 0.07752 & 0.07412 & 0.07168 \\
\hline
\end{tabular}

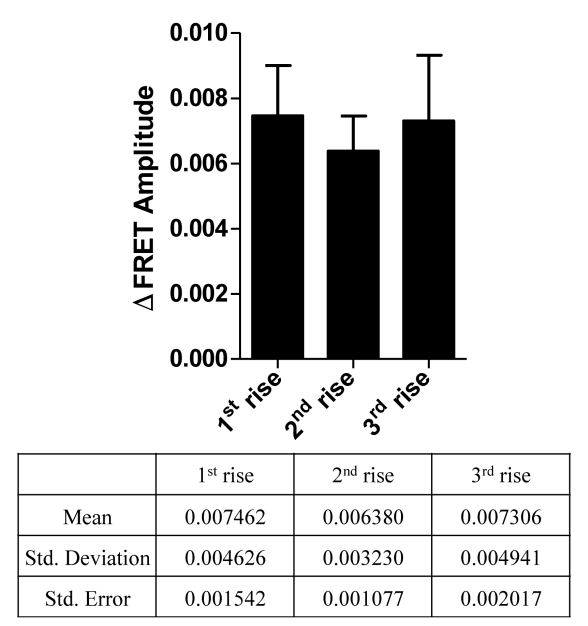

\begin{tabular}{|c|c|c|c|}
\hline & $1^{\text {st }}$ rise & $2^{\text {nd }}$ rise & $3^{\text {rd }}$ rise \\
\hline Mean & 0.007462 & 0.006380 & 0.007306 \\
\hline Std. Deviation & 0.004626 & 0.003230 & 0.004941 \\
\hline Std. Error & 0.001542 & 0.001077 & 0.002017 \\
\hline
\end{tabular}

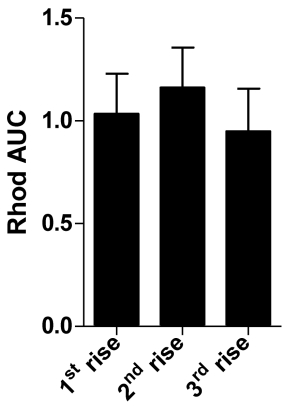

\begin{tabular}{|c|c|c|c|}
\hline & $1^{\text {st }}$ rise & $2^{\text {nd }}$ rise & $3^{\text {rd }}$ rise \\
\hline Mean & 1.035 & 1.161 & 0.9492 \\
\hline Std. Deviation & 0.5829 & 0.5877 & 0.5496 \\
\hline Std. Error & 0.1943 & 0.1959 & 0.2077 \\
\hline
\end{tabular}

2 Figure 6 - figure supplement 1. Quantification of Rhod-2 and FRET signals for FRESCA during PLC $\zeta$ induced $\mathrm{Ca}^{2+}$ rises. Three $\mathrm{Ca}^{2+}$ rises were quantified. The " $1{ }^{\text {st }}$ 4 rise" is that which induced the first FRET response, and then the subsequent 2 rises were measured. 


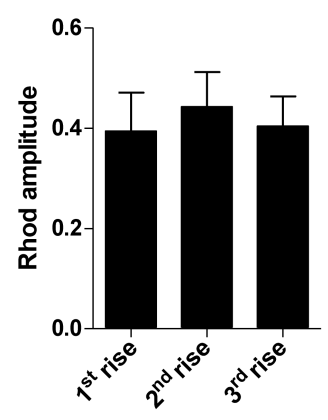

\begin{tabular}{|c|c|c|c|}
\hline & $1^{\text {st }}$ rise & $2^{\text {nd }}$ rise & $3^{\text {rd }}$ rise \\
\hline Mean & 0.3936 & 0.4425 & 0.4035 \\
\hline Std. Deviation & 0.2439 & 0.2074 & 0.1791 \\
\hline Std. Error & 0.07713 & 0.06913 & 0.05971 \\
\hline
\end{tabular}

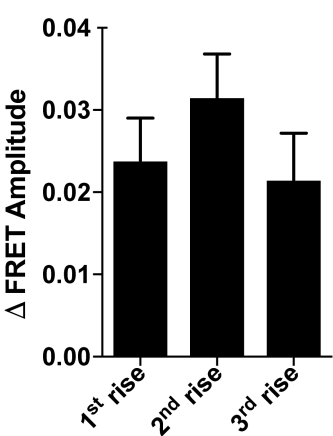

\begin{tabular}{|c|c|c|c|}
\hline & $1^{\text {st }}$ rise & $2^{\text {nd }}$ rise & $3^{\text {rd }}$ rise \\
\hline Mean & 0.02385 & 0.03155 & 0.02152 \\
\hline Std. Deviation & 0.01638 & 0.01575 & 0.01495 \\
\hline Std. Error & 0.005181 & 0.00525 & 0.005649 \\
\hline
\end{tabular}

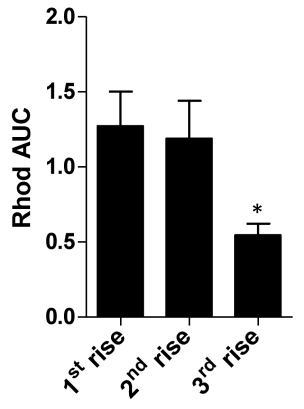

\begin{tabular}{|c|c|c|c|}
\hline & $1^{\text {st }}$ rise & $2^{\text {nd }}$ rise & $3^{\text {rd }}$ rise \\
\hline Mean & 1.272 & 1.190 & 0.6574 \\
\hline Std. Deviation & 0.7261 & 0.7550 & 0.2639 \\
\hline Std. Error & 0.2296 & 0.2517 & 0.08797 \\
\hline
\end{tabular}

Figure 6 - figure supplement 2. Quantification of Rhod-2 and FRET signals for

4 Camui during PLC $\zeta$ induced $\mathrm{Ca}^{2+}$ rises. Three $\mathrm{Ca}^{2+}$ rises were quantified. The " $1{ }^{\text {st }}$ rise" is that which induced the first FRET response, and then the subsequent 2 rises were measured. Differences were considered significant at $\mathrm{P}<0.05(*)$.

\section{CONCLUDING REMARKS}

It has been appreciated for decades that both $\mathrm{Ca}^{2+}$ oscillations and CaMKII activation in

10 mouse eggs is crucial to fertilization and initiation of embryo development. Here, we provide an analysis of CaMKII activation in real-time in eggs using FRET-based CaMKII

12 biosensors. Importantly, our new biosensor, FRESCA, allowed us to monitor endogenous CaMKII (CaMKII $\gamma 3$ and $\gamma \mathrm{J})$ activation in real-time as a consequence of different 
activation stimuli (ionomycin, $\mathrm{Sr}^{2+}$, and $\mathrm{PLC} \zeta$ ). The FRESCA response was noticeably

2 different from the Camui sensor, which reports on CaMKII $\alpha$. When different $\mathrm{Ca}^{2+}$ oscillation patterns are induced, we observe subsequent differences in CaMKII activity.

4 From our data, it is clear that both the (i) pattern of $\mathrm{Ca}^{2+}$ oscillations as well as the (ii) specific CaMKII isoform responding play a role in CaMKII activation.

The pivotal role of CaMKII activation in causing release of the meiotic arrest and

8 activation of the embryonic developmental program in vertebrates was recently and more specifically evidenced by careful mass spectrometry experiments (Presler et al., 2017).

10 This study showed that soon after fertilization, and temporally coinciding with the $\mathrm{Ca}^{2+}$ wave, there is a strong increase in protein phosphorylation that far outweighs the

12 biochemical changes caused by protein degradation that accompanies fertilization. Remarkably, the study also found that $25 \%$ of the phosphorylated sites matched the

14 minimal phosphorylation motif of CaMKII. It is therefore important to determine how $\mathrm{Ca}^{2+}$ rises turn on CaMKII activity, and what parameter(s) of individual rises within an

16 oscillatory pattern are necessary for periodic and consistent stimulation of its activity. We propose that the magnitude of the initial activation of CaMKII depends on the magnitude

18 of the stimulus and on internal regulation of CaMKII, which is largely based on the variable linker region. Knowing the minimal $\mathrm{Ca}^{2+}$ signal that increases the activity of

20 CaMKII $\gamma$ is important as we seek to develop more physiological methods of parthenogenetic activation to treat some cases of infertility. 
More broadly, now that we have demonstrated the utility of FRESCA in mouse eggs, this

2 opens the door to measuring endogenous CaMKII activity in other cell types, such as neurons and cardiomyocytes. CaMKII activation has been heavily studied in vitro (Chao

4 et al., 2010; Chao et al., 2011; Rosenberg, Deindl, Sung, Nairn, \& Kuriyan, 2005), and it is intriguing to also consider the potential effects of subunit exchange in cellular

6 conditions (Bhattacharyya et al., 2016; Stratton et al., 2013). It will be necessary to increase the signal to noise ratio of the FRESCA sensor in order to achieve a more robust

8 signal for accurate quantification of kinetics and amplitudes. Once this is accomplished, we believe that FRESCA will provide new insights into CaMKII activity in cells and

10 allow us to unravel the complexity of this unique protein kinase.

\section{Acknowledgements}

We thank Changli He for assistance on RNA purification. We thank Allosteros

14 therapeutics for providing AS105, AS461 and Howard Schulman for helpful discussion. We also thank Peter Chien, Eric Strieter, Scott Garman for discussions and John Kuriyan

16 for helpful comments on the manuscript. 


\section{MATERIALS AND METHODS}

\section{$2 \quad$ Plasmid design}

In order to accommodate the requirements for FHA2 binding (Durocher et al., 2000),

4 syntide was modified from PLARTLSVAGLPGKK to PLARALTVAGLPGKK to create syntide-2. Syntide-2 was generated by annealing

6 GATCCGGCGGCGCCGGCGGCGGCccgetggcgegcgectgaccgtggegggectgecgggcaaaaa aGGC and

8 GGCCGCCttttttgcceggcaggccegccacggtcagggegcgcgccagcggGCCGCCGCCGGCGCCG CCG (IDT), which produced BamHI site at the 5' end and a NotI site on the 3' end. This

10 product was phosphorylated (Ambion Pnk), purified (Thermo Fisher) and then ligated using T4 DNA ligase (Invitrogen) into a plasmid encoding the Aurora kinase FRET

12 sensor (kind gift from Thomas Maresca). The final FRESCA sensor (with syntide-2 in place of the Aurora substrate) was cloned into pCDNA3.1.

\section{HEK 293T Cell culture}

16 All HEK293T cell cultures were grown in Dulbecco's Modified Eagle's Medium (Sigma) supplemented with $10 \%$ fetal bovine serum (Sigma) and maintained at $37^{\circ} \mathrm{C}$ and $5 \%$

18 carbon dioxide levels. The identity of these cells was authenticated by ATCC (CRL-3216 ATC 293T, Lot \#63226319). Cells were transfected using Lipofectamine ${ }^{\circledR} 2000$ Reagent

20 (Invitrogen) and $150 \mathrm{ng}$ of DNA constructs. 


\section{Collection of mouse eggs}

2 Metaphase II (MII) eggs were collected from the oviducts of 6- to 10-week-old CD-1 female mice $12-14 \mathrm{~h}$ after administration of $5 \mathrm{IU}$ of human chorionic gonadotropin

4 (hCG), which was administered 46-48h after the injection of 5 IU of pregnant mare serum gonadotropin (PMSG; Sigma; Saint Louis, MO). Cumulus cells were removed

6 with $0.1 \%$ bovine testes hyaluronidase (Sigma). MII eggs were placed in KSOM with amino acids (Millipore Sigma) under mineral oil at $37^{\circ} \mathrm{C}$ in a humidified atmosphere of

$85 \% \mathrm{CO}_{2}$ until the time of monitoring. All animal procedures were performed according to research animal protocols approved by the University of Massachusetts Institutional

10 Animal Care and Use Committee.

\section{Preparation of cRNAs and Microinjections}

The sequences encoding Camui and FRESCA were subcloned into a pcDNA6 vector

14 (pcDNA6/Myc-His B; Invitrogen, Carlsbad, CA) between the XhoI and PmeI restriction sites. Mouse PLC $\zeta$ was a kind gift from Dr K. Fukami (Tokyo University of Pharmacy

16 and Life Science, Japan) and subcloned into a PCS2+ vector, as previously described by us (Kurokawa et al., 2007). Plasmids were linearized with a restriction enzyme

18 downstream of the insert to be transcribed and cDNAs were in vitro transcribed using the T7 or SP6 mMESSAGE mMACHINE Kit (Ambion, Austin, TX) according to the

20 promoter present in the construct. A Poly (A)-tail was added to the mRNAs using a Tailing Kit (Ambion) and poly(A)-tailed RNAs were eluted with RNAase-free water and

22 stored in aliquots at $-80^{\circ} \mathrm{C}$. Microinjections were performed as described previously (Lee et al., 2016). cRNAs were centrifuged, and the top 1-2 $\mu$ l was used to prepare micro 
drops from which glass micropipettes were loaded by aspiration. cRNA were delivered

2 into eggs by pneumatic pressure (PLI-100 picoinjector, Harvard Apparatus, Cambridge, MA). Each egg received 5-10 pl, which is approximately $1-3 \%$ of the total volume of the

4 egg. Injected MII eggs were allowed for translation up to $4 \mathrm{~h}$ in KSOM. Group of eggs were injected with mouse PLC $\zeta$ after $4 \mathrm{~h}$ of FRET construct injection.

6

\section{FRET and Calcium imaging}

8 To estimate relative changes in the cytoplasmic activity of Camui and/or FRESCA, emission ratio imaging of the Camui and FRESCA (YFP/CFP) was performed using a

10 CFP excitation filter, dichroic beam splitter, CFP and YFP emission filters (Chroma technology, Rockingham, VT; ET436/20X, 89007bs, ET480/40m and ET535/30m). To

12 measure Camui and/or FRESCA activity and $\left[\mathrm{Ca}^{2+}\right]_{\mathrm{i}}$ simultaneously, eggs that had been injected with Camui and/or FRESCA cRNAs were loaded $\sim 4$ hours post-injection with 1

$14 \mu \mathrm{M}$ Rhod-2AM supplemented with $0.02 \%$ pluronic acid for 20 minutes at RT. Eggs were then attached on glass-bottom dishes (MatTek Corp., Ashland, MA) and placed on the

16 stage of an inverted microscope. CFP, YFP and Rhod-2 intensities were collected every 20 second by a cooled Photometrics SenSys CCD camera (Roper Scientific, Tucson,

$18 \mathrm{AZ}$ ). The rotation of excitation and emission filter wheels was controlled using the MAC5000 filter wheel/shutter control box (Ludl) and NIS-elements software (Nikon).

20 Imaging was performed on an inverted epifluorescence microscope (Nikon Eclipse TE 300, Analis Ghent, Belgium) using a 20x objective. For studies where ionomycin was

22 used to induce $\mathrm{Ca}^{2+}$ responses, eggs were transferred into a $360 \mu \mathrm{Ca}^{2+}$-free TL-Hepes drop on a glass bottom dish, after which and following a brief monitoring period to 
determine baseline $\left[\mathrm{Ca}^{2+}\right]_{\mathrm{i}}$ values, different concentrations of ionomycin were added and

$2 \mathrm{Ca}^{2+}$ responses monitored. For $\mathrm{Sr}^{2+}$ studies, eggs were transferred into a $\mathrm{Ca}^{2+}$ - free TLHepes, containing $10 \mathrm{mM} \mathrm{Sr}^{2+}$. In cases where $\left[\mathrm{Ca}^{2+}\right]_{\mathrm{i}}$ oscillations were induced by

4 injection of mPLC $\zeta$ cRNA, eggs were placed in TL-Hepes media containing $2 \mathrm{mM} \mathrm{Ca}^{2+}$ within 20 minutes of the injection of mPLC $\zeta$ which occurred 4 hours post-injection of the

6 FRET constructs (Camui or FRESCA).

\section{Pharmacological tests in mouse eggs}

Mouse eggs were transferred to $\mathrm{Ca}^{2+}$ free TL-Hepes containing desired concetnrations of

10 pharmacological compounds 5 min prior to $\mathrm{Ca}^{2+}$ imaging. FRET (YFP/CFP) was monitored simultaneously with $\mathrm{Ca}^{2+}$ (rhodamine signal). First, we determined how much

12 inhibitor could be added without affecting $\mathrm{Ca}^{2+}$ entry. Concentrations of inhibitors were chosen based on this information as well as what was used in previous studies, see text

14 for references. All media was $\mathrm{Ca}^{2+}$ free with the exception of PMA. The following concentrations were used: KN93 (0.5 $\mu \mathrm{M})$, GO6983 (3 $\mu \mathrm{M})$, Bim1 (5 $\mu \mathrm{M})$, PMA (1 $\mu \mathrm{M})$,

16 AS105 $(5 \mu \mathrm{M})$, AS461 $(5 \mu \mathrm{M})$. AS105 has not been used in mouse eggs, so we adjusted the concentration to a level where the $\mathrm{Ca}^{2+}$ entry was not affected. Eggs with the first 4

18 compounds added were stimulated with $0.5 \mu \mathrm{M}$ ionomycin 5 min after monitoring started, while the eggs with AS compounds were stimulated with $2.5 \mu \mathrm{M}$ ionomycin.

20 Side by side controls were performed under the same conditions ( $0.5 \mu \mathrm{M}$ vs. $2.5 \mu \mathrm{M}$ ionomycin). 


\section{Data processing \& statistical analyses}

2 Graphs reporting FRET changes and $\mathrm{Ca}^{2+}$ responses were prepared using the values of the YFP $(436 \times 535) / C F P(436 \times 480)$ ratios on the left axis, whereas Rhod-2 values were

4 calculated using the following formula (F)/F0 (actual value at $\mathrm{x}$ time/average baseline values for the first 2 minutes of monitoring) and the scale placed on the right axis. Values

6 from three or more experiments performed on different batches of eggs are presented as means \pm s.e.m and were analyzed by the Student's t-test. Differences were considered

8 significant at $\mathrm{P}<0.05$.

10 Table 1. Replicates in Camui experiments

\begin{tabular}{|c|c|c|c|c|}
\hline Camui & Experiment type & \# of replicates & \# of mice & \# of total eggs \\
\hline & Iono $0.5 \mu \mathrm{M}$ & $3 \mathrm{x}$ & 2 & 12 \\
\hline & Iono $2.5 \mu \mathrm{M}$ & $4 \mathrm{x}$ & 3 & 16 \\
\hline & Iono $5.0 \mu \mathrm{M}$ & $3 \mathrm{x}$ & 2 & 12 \\
\hline & & & & \\
\hline & $\mathrm{Sr}^{2+}$ & $2 \mathrm{x}$ & 3 & 11 \\
\hline & & & & 16 \\
\hline
\end{tabular}


Table 2. Replicates in FRESCA experiments

\begin{tabular}{|c|c|c|c|c|}
\hline FRESCA & Experiment type & \# of replicates & \# of mice & \# of total eggs \\
\hline & Iono $0.5 \mu \mathrm{M}$ & $4 \mathrm{x}$ & 2 & 16 \\
\hline & Iono $2.5 \mu \mathrm{M}$ & $4 \mathrm{x}$ & 3 & 16 \\
\hline & Iono $5.0 \mu \mathrm{M}$ & $3 x$ & 2 & 8 \\
\hline & $\mathrm{Sr}^{2+}$ & $3 x$ & 3 & 22 \\
\hline & PLCל & $2 \mathrm{x}$ & 3 & 9 \\
\hline & & & & \\
\hline \multicolumn{5}{|l|}{$\begin{array}{l}\text { Added } \\
\text { compounds }\end{array}$} \\
\hline \multirow[t]{8}{*}{ Control } & Iono $0.5 \mu \mathrm{M}$ & $5 x$ & 2 & 27 \\
\hline & Iono $2.5 \mu \mathrm{M}$ & $2 \mathrm{x}$ & 2 & 13 \\
\hline & PMA & $2 \mathrm{x}$ & 2 & 10 \\
\hline & BIM1 & $1 \mathrm{x}$ & 2 & 5 \\
\hline & KN93 & $2 \mathrm{x}$ & 2 & 10 \\
\hline & GO6983 & $2 \mathrm{x}$ & 2 & 9 \\
\hline & AS105 & $2 x$ & 2 & 10 \\
\hline & AS461 & $2 \mathrm{x}$ & 2 & 15 \\
\hline
\end{tabular}

2

4

6

8

10 


\section{REFERENCES}

2 Backs, J., Backs, T., Neef, S., Kreusser, M. M., Lehmann, L. H., Patrick, D. M., ... Olson, E. N. (2009). The delta isoform of CaM kinase II is required for pathological

4

6 cardiac hypertrophy and remodeling after pressure overload. Proc Natl Acad Sci U S A, 106(7), 2342-2347. doi:10.1073/pnas.0813013106

Backs, J., Stein, P., Backs, T., Duncan, F. E., Grueter, C. E., McAnally, J., .. Olson, E. N. (2010). The gamma isoform of CaM kinase II controls mouse egg activation by regulating cell cycle resumption. Proc Natl Acad Sci U S A, 107(1), 81-86. doi:10.1073/pnas.0912658106

Bayer, K. U., De Koninck, P., \& Schulman, H. (2002). Alternative splicing modulates the frequency-dependent response of CaMKII to $\mathrm{Ca}(2+)$ oscillations. EMBO J, 21(14), 3590-3597. doi:10.1093/emboj/cdf360 [doi]

Bhattacharyya, M., Stratton, M. M., Going, C. C., McSpadden, E. D., Huang, Y., Susa, A. C., ... Kuriyan, J. (2016). Molecular mechanism of activation-triggered subunit exchange in $\mathrm{Ca} /$ calmodulin-dependent protein kinase II. Elife, 5. doi:10.7554/eLife.13405

Bosmikich, A., \& Whittingham, D. G. (1995). Analysis of the Chromosome Complement of Frozen-Thawed Mouse Oocytes after Parthenogenetic Activation. Molecular Reproduction and Development, 42(2), 254-260. doi:DOI $10.1002 /$ mrd.1080420215

Carvacho, I., Lee, H. C., Fissore, R. A., \& Clapham, D. E. (2013). TRPV3 Channels Mediate Strontium-Induced Mouse-Egg Activation. Cell Reports, 5(5), 13751386. doi:10.1016/j.celrep.2013.11.007

Chang, H. Y., Minahan, K., Merriman, J. A., \& Jones, K. T. (2009). Calmodulindependent protein kinase gamma 3 (CamKII gamma 3) mediates the cell cycle resumption of metaphase II eggs in mouse. Development, 136(24), 4077-4081. doi:10.1242/dev.042143

Chao, L. H., Pellicena, P., Deindl, S., Barclay, L. A., Schulman, H., \& Kuriyan, J. (2010). Intersubunit capture of regulatory segments is a component of cooperative CaMKII activation. Nat Struct Mol Biol, 17(3), 264-272. doi:nsmb.1751 [pii] $10.1038 /$ nsmb.1751 [doi]

Chao, L. H., Stratton, M. M., Lee, I. H., Rosenberg, O. S., Levitz, J., Mandell, D. J., ... Kuriyan, J. (2011). A mechanism for tunable autoinhibition in the structure of a human Ca2+/calmodulin- dependent kinase II holoenzyme. Cell, 146(5), 732-745. doi:10.1016/j.cell.2011.07.038 
2 Cuthbertson, K. S., Whittingham, D. G., \& Cobbold, P. H. (1981). Free Ca2+ increases in exponential phases during mouse oocyte activation. Nature, 294(5843),

4

De Koninck, P., \& Schulman, H. (1998). Sensitivity of CaM kinase II to the frequency of Ca2+ oscillations. Science, 279(5348), 227-230.

Deguchi, R., Shirakawa, H., Oda, S., Mohri, T., \& Miyazaki, S. (2000). Spatiotemporal analysis of $\mathrm{Ca}(2+)$ waves in relation to the sperm entry site and animalvegetal axis during $\mathrm{Ca}(2+)$ oscillations in fertilized mouse eggs. Dev Biol, 218(2), 299-313. doi:10.1006/dbio.1999.9573

Ducibella, T., Huneau, D., Angelichio, E., Xu, Z., Schultz, R. M., Kopf, G. S., . . Ozil, J. P. (2002). Egg-to-embryo transition is driven by differential responses to $\mathrm{Ca} 2+$ oscillation number. Developmental Biology, 250(2), 280-291. doi:10.1006/dbio.2002.0788

Durocher, D., Taylor, I. A., Sarbassova, D., Haire, L. F., Westcott, S. L., Jackson, S. P., . . Yaffe, M. B. (2000). The molecular basis of FHA domain:phosphopeptide binding specificity and implications for phospho-dependent signaling mechanisms. Mol Cell, 6(5), 1169-1182.

Eisner, D. A., Caldwell, J. L., Kistamas, K., \& Trafford, A. W. (2017). Calcium and Excitation-Contraction Coupling in the Heart. Circ Res, 121(2), 181-195. doi:10.1161/CIRCRESAHA.117.310230

Erickson, J. R., Patel, R., Ferguson, A., Bossuyt, J., \& Bers, D. M. (2011). Fluorescence resonance energy transfer-based sensor Camui provides new insight into mechanisms of calcium/calmodulin-dependent protein kinase II activation in intact cardiomyocytes. Circ Res, 109(7), 729-738. doi:10.1161/circresaha.111.247148

Escoffier, J., Lee, H. C., Yassine, S., Zouari, R., Martinez, G., Karaouzene, T., ... Arnoult, C. (2016). Homozygous mutation of PLCZ1 leads to defective human oocyte activation and infertility that is not rescued by the WW-binding protein PAWP. Human Molecular Genetics, 25(5), 878-891. doi:10.1093/hmg/ddv617

Fissore, R. A., Dobrinsky, J. R., Balise, J. J., Duby, R. T., \& Robl, J. M. (1992). Patterns of intracellular Ca2+ concentrations in fertilized bovine eggs. Biol Reprod, 47(6), 960-969.

Gou, X., Wang, W., Zou, S., Qi, Y., \& Xu, Y. (2018). Protein kinase C epsilon mediates the inhibition of angiotensin II on the slowly activating delayed-rectifier 
potassium current through channel phosphorylation. J Mol Cell Cardiol, 116, 165-174. doi:10.1016/j.yjmcc.2018.02.010

Halet, G. (2004). PKC signaling at fertilization in mammalian eggs. Biochim Biophys Acta, 1742(1-3), 185-189. doi:10.1016/j.bbamcr.2004.09.012

Hatch, K. R., \& Capco, D. G. (2001). Colocalization of CaM KII and MAP kinase on architectural elements of the mouse egg: potentiation of MAP kinase activity by CaM KII. Mol Reprod Dev, 58(1), 69-77. doi:10.1002/10982795(200101)58:1<69::AID-MRD10>3.0.CO;2-0

Herring, B. E., \& Nicoll, R. A. (2016). Long-Term Potentiation: From CaMKII to AMPA Receptor Trafficking. Annu Rev Physiol, 78, 351-365. doi:10.1146/annurevphysiol-021014-071753

Jones, K. T., Carroll, J., Merriman, J. A., Whittingham, D. G., \& Kono, T. (1995). Repetitive Sperm-Induced Ca2+ Transients in Mouse Oocytes Are Cell-Cycle Dependent. Development, 121(10), 3259-3266.

Kline, D., \& Kline, J. T. (1992). Repetitive Calcium Transients and the Role of Calcium in Exocytosis and Cell-Cycle Activation in the Mouse Egg. Developmental Biology, 149(1), 80-89. doi:Doi 10.1016/0012-1606(92)90265-I

Kwok, S., Lee, C., Sanchez, S. A., Hazlett, T. L., Gratton, E., \& Hayashi, Y. (2008). Genetically encoded probe for fluorescence lifetime imaging of CaMKII activity. Biochem Biophys Res Commun, 369(2), 519-525. doi:10.1016/j.bbrc.2008.02.070

Liu, D., Vader, G., Vromans, M. J., Lampson, M. A., \& Lens, S. M. (2009). Sensing chromosome bi-orientation by spatial separation of aurora B kinase from kinetochore substrates. Science, 323(5919), 1350-1353. doi:10.1126/science. 1167000

Madgwick, S., Levasseur, M., \& Jones, K. T. (2005). Calmodulin-dependent protein kinase II, and not protein kinase $C$, is sufficient for triggering cell-cycle resumption in mammalian eggs. Journal of Cell Science, 118(Pt 17), 38493859. doi: $10.1242 /$ jcs.02506

Markoulaki, S., Matson, S., \& Ducibella, T. (2004). Fertilization stimulates longlasting oscillations of CaMKII activity in mouse eggs. Dev Biol, 272(1), 15-25. doi:10.1016/j.ydbio.2004.04.008

Medvedev, S., Stein, P., \& Schultz, R. M. (2014). Specificity of calcium/calmodulindependent protein kinases in mouse egg activation. Cell Cycle, 13(9), 14821488. doi:10.4161/cc.28432 
2 Meyer, T., Hanson, P. I., Stryer, L., \& Schulman, H. (1992). Calmodulin trapping by calcium-calmodulin-dependent protein kinase. Science, 256(5060), 1199-

$4 \quad 1202$.

6 Miao, Y. L., Stein, P., Jefferson, W. N., Padilla-Banks, E., \& Williams, C. J. (2012). Calcium influx-mediated signaling is required for complete mouse egg activation. Proceedings of the National Academy of Sciences of the United States of America, 109(11), 4169-4174. doi:10.1073/pnas.1112333109

Miyazaki, S., Yuzaki, M., Nakada, K., Shirakawa, H., Nakanishi, S., Nakade, S., \& Mikoshiba, K. (1992). Block of Ca2+ Wave and Ca2+ Oscillation by Antibody to the Inositol 1,4,5-Trisphosphate Receptor in Fertilized Hamster Eggs.

16 Mollova, M. Y., Katus, H. A., \& Backs, J. (2015). Regulation of CaMKII signaling in cardiovascular disease. Front Pharmacol, 6, 178. doi:10.3389/fphar.2015.00178

Neef, S., Steffens, A., Pellicena, P., Mustroph, J., Lebek, S., Ort, K. R., . . Maier, L. S. (2018). Improvement of cardiomyocyte function by a novel pyrimidine-

Nutt, L. K., Margolis, S. S., Jensen, M., Herman, C. E., Dunphy, W. G., Rathmell, J. C., \& based CaMKII-inhibitor. J Mol Cell Cardiol, 115, 73-81. doi:10.1016/j.yjmcc.2017.12.015 Kornbluth, S. (2005). Metabolic regulation of oocyte cell death through the CaMKII-mediated phosphorylation of caspase-2. Cell, 123(1), 89-103. doi:10.1016/j.cell.2005.07.032

Ozil, J. P., Markoulaki, S., Toth, S., Matson, S., Banrezes, B., Knott, J. G., . . . Ducibella, T. (2005). Egg activation events are regulated by the duration of a sustained [Ca2+]cyt signal in the mouse. Dev Biol, 282(1), 39-54. doi:10.1016/j.ydbio.2005.02.035

Presler, M., Van Itallie, E., Klein, A. M., Kunz, R., Coughlin, M. L., Peshkin, L., . . . Kirschner, M. W. (2017). Proteomics of phosphorylation and protein dynamics during fertilization and meiotic exit in the Xenopus egg. Proc Natl Acad Sci U S A, 114(50), E10838-E10847. doi:10.1073/pnas.1709207114

Robison, A. J. (2014). Emerging role of CaMKII in neuropsychiatric disease. Trends Neurosci, 37(11), 653-662. doi:10.1016/j.tins.2014.07.001

Rokita, A. G., \& Anderson, M. E. (2012). New Therapeutic Targets in Cardiology: Arrhythmias and Ca2+/Calmodulin-Dependent Kinase II (CaMKII). Circulation, 126(17), 2125-2139. doi:10.1161/circulationaha.112.124990 
2 Rosenberg, O. S., Deindl, S., Comolli, L. R., Hoelz, A., Downing, K. H., Nairn, A. C., \& Kuriyan, J. (2006). Oligomerization states of the association domain and the

4 holoenyzme of Ca2+/CaM kinase II. FEBS J, 273(4), 682-694. doi:EJB5088 [pii]

\subsection{1/j.1742-4658.2005.05088.x [doi]}

Rosenberg, O. S., Deindl, S., Sung, R. J., Nairn, A. C., \& Kuriyan, J. (2005). Structure of the autoinhibited kinase domain of CaMKII and SAXS analysis of the holoenzyme. Cell, 123(5), 849-860. doi:S0092-8674(05)01173-6 [pii] 10.1016/j.cell.2005.10.029 [doi]

Rutecki, P. A. (1992). Neuronal excitability: voltage-dependent currents and synaptic transmission. J Clin Neurophysiol, 9(2), 195-211.

Saunders, C. M., Larman, M. G., Parrington, J., Cox, L. J., Royse, J., Blayney, L. M., . . Lai, F. A. (2002). PLC zeta: a sperm-specific trigger of $\mathrm{Ca}(2+)$ oscillations in eggs and embryo development. Development, 129(15), 3533-3544.

Shonesy, B. C., Jalan-Sakrikar, N., Cavener, V. S., \& Colbran, R. J. (2014). CaMKII: a molecular substrate for synaptic plasticity and memory. Prog Mol Biol Transl Sci, 122, 61-87. doi:10.1016/B978-0-12-420170-5.00003-9

Smyth, J. T., Abbott, A. L., Lee, B., Sienaert, I., Kasri, N. N., De Smedt, H., . . Fissore, R. A. (2002). Inhibition of the inositol trisphosphate receptor of mouse eggs and A7r5 cells by KN-93 via a mechanism unrelated to $\mathrm{Ca} 2+$ /calmodulindependent protein kinase II antagonism.J Biol Chem, 277(38), 35061-35070. doi:10.1074/jbc.M202928200

Steinkellner, T., Yang, J. W., Montgomery, T. R., Chen, W. Q., Winkler, M. T., Sucic, S., . . . Kudlacek, O. (2012). $\mathrm{Ca}(2+)$ /calmodulin-dependent protein kinase IIalpha (alphaCaMKII) controls the activity of the dopamine transporter: implications for Angelman syndrome.J Biol Chem, 287(35), 29627-29635. doi:10.1074/jbc.M112.367219

Stratton, M., Lee, I. H., Bhattacharyya, M., Christensen, S. M., Chao, L. H., Schulman, H., ... Kuriyan, J. (2013). Activation-triggered subunit exchange between CaMKII holoenzymes facilitates the spread of kinase activity. Elife, 3(0), e01610. doi:10.7554/eLife.01610

Suzuki, M., Hara, Y., Takagi, C., Yamamoto, T. S., \& Ueno, N. (2011). MID1 and MID2 are required for Xenopus neural tube closure through the regulation of microtubule organization (vol 137, pg 2329, 2010). Development, 138(2), 385-385. doi:10.1242/dev.062976 
Swann, K., \& Lai, F. A. (2013). PLCzeta and the initiation of $\mathrm{Ca}(2+)$ oscillations in

4

14 Wang, S. F., Kou, Z. H., Jing, Z. Y., Zhang, Y., Guo, X. Z., Dong, M. Q., ... Gao, S. R. (2010). Proteome of mouse oocytes at different developmental stages. Proceedings of fertilizing mammalian eggs. Cell Calcium, 53(1), 55-62. doi:10.1016/j.ceca.2012.11.001

Takao, K., Okamoto, K., Nakagawa, T., Neve, R. L., Nagai, T., Miyawaki, A., ... Hayashi, Y. (2005). Visualization of synaptic Ca2+ /calmodulin-dependent protein kinase II activity in living neurons. J Neurosci, 25(12), 3107-3112. doi:10.1523/jneurosci.0085-05.2005

Tu, S., Okamoto, S., Lipton, S. A., \& Xu, H. (2014). Oligomeric Abeta-induced synaptic dysfunction in Alzheimer's disease. Mol Neurodegener, 9, 48. doi:10.1186/1750-1326-9-48 the National Academy of Sciences of the United States of America, 107(41), 17639-17644. doi:10.1073/pnas.1013185107

Yoon, S. Y., Jellerette, T., Salicioni, A. M., Lee, H. C., Yoo, M. S., Coward, K., . . Fissore, R. A. (2008). Human sperm devoid of PLC, zeta 1 fail to induce $\mathrm{Ca}(2+)$ release and are unable to initiate the first step of embryo development. J Clin Invest, 118(11), 3671-3681. doi:10.1172/JCI36942 